\title{
Joves adults d'origen extracomunitari a Barcelona. Construcció de la identitat i processos d'inclusió i exclusió social
}

\author{
Núria Roca i Caparà \\ EMIGRA - CER Migracions. Universitat Autònoma de Barcelona \\ Escola Universitària d'Infermeria Sant Joan de Déu. Universitat de Barcelona \\ nroca@santjoandedeu.edu.es
}

\section{Resum}

En aquest article, s'hi presenten una part dels resultats de la recerca qualitativa realitzada a Barcelona amb fills i filles de famílies immigrades extracomunitàries. S'hi estudien els processos de construcció de la identitat en relació amb les situacions de discriminació viscudes. Els objectius principals són: 1. Reconstruir els processos identitaris que elaboren els fills i les filles de persones immigrades procedents de contextos socioculturals diversos a la ciutat de Barcelona. 2. Analitzar les interaccions que es donen entre les experiències d'inclusió i exclusió social i els processos identitaris d'aquests joves.

S'han realitzat 31 entrevistes en profunditat, semiestructurades, a joves d'orígens diferents. Els resultats indiquen que desenvolupen una identitat cultural flexible, oberta i múltiple que els permet afrontar situacions de discriminació per origen i classe social. Tenen una gran capacitat d'adaptació a contextos multiculturals i es vinculen amb elements de la cultura familiar i de la societat on creixen com a persones. Les situacions de discriminació, que alguns pateixen, impacten en les seves identitats i pertinences, però elaboren estratègies de superació i de resistència.

Paraules clau: fills i filles d'immigrants; families immigrades; flexibilitat identitària; discriminació; inclusió social.

\section{Abstract. Young Adults of Non-EU Origin: The Construction of Identity and Processes of Social Inclusion and Exclusion}

This article presents some results of qualitative research carried out in Barcelona among children of non-EU immigrant families. We study the processes of identity construction in relation to situations of discrimination. The main objectives are twofold: to rebuild the identity processes that children of immigrants from various sociocultural contexts in the city of Barcelona experience and to analyze the interactions that occur between the experiences of social inclusion-exclusion and the identity processes of these young people. To do so, we conducted 31 in-depth, semi-structured interviews of youth from different backgrounds. The results indicate that they develop a flexible cultural identity that is open and adaptable to multiple cultures and which allows them to face situations of discrimination due to their background and social class. We find that these young people have 
a great capacity to adapt to multicultural contexts, and are linked with elements of the family culture and society where they grow as individuals. The situations of discrimination that some of them experience have an impact on their identities and sense of belonging. However, they develop strategies to overcome and resist them.

Keywords: children of immigrants; immigrant families; identity flexibility; discrimination; social inclusion.

\section{Sumari}

1. Introducció 6. Processos de construcció identitària.

2. Context Una proposta de classificació

3. Marc teòric 7. Conclusions

4. Plantejament de la recerca

Referències bibliogràfiques

5. Identitats flexibles i discriminació

\section{Introducció}

En aquest article, s'hi presenta una part dels resultats de la recerca qualitativa Construint identitats flexibles. Joves adults ${ }^{1}$ d'origen extracomunitari entre processos d'inclusió i exclusió social (Roca i Caparà, 2009), que té per objectiu conèixer i descriure quin és el procés de construcció de la identitat dels fills i les filles ${ }^{2}$ de famílies immigrades i de quina manera influeixen els contextos d'inclusió i exclusió en les seves trajectòries de vida i en aquesta construcció. L'interès a examinar les identitats d'aquests joves respon al fet que, malgrat que es tracti d'un col-lectiu emergent en l'escenari social, encara està poc visibilitzat ${ }^{3}$. En

1. La joventut és una etapa del cicle vital en prolongació. Es caracteritza per discontinuïtats, inseguretats i retrocessos. Els joves actuals han d'afrontar situacions de dificultat que visualitzen com a personals i individuals i no pas com a components de l'estructura social (Furlong, 2000). L'Informe Juventud en España 2008 considera el grup d'edat entre $15 \mathrm{i}$ 29 anys com a específic de la joventut. Podem considerar com a joves adults els que han arribat a la majoria d'edat i, per tant, se situen entre els 18 i els 29 anys.

2. Durant el desenvolupament del treball, em referiré a «fills i filles de persones immigrades» $\mathrm{i}$ a «autòctons». En el primer cas, es tracta de nois i noies nascuts al país d'origen o al de destinació, fills i filles de famílies d'origen estranger (extracomunitari). Amb el terme autòctons, em refereixo a persones nascudes al país de destinació, sense família procedent de l'estranger. Voldria deixar clar que aquestes categories són utilitzades per especificar a qui em refereixo en cada moment $i$ en cap cas donar per suposat que són categories tancades i homogènies. D'altra banda, cal destacar que utilitzo la categoria «fills i filles de persones immigrades» en comptes de "segona generació d'immigrants» perquè entenc que, en tractar-se d'una recerca qualitativa, aquest qualificatiu comporta el perill d'homogeneïtzar un col-lectiu heterogeni. S'entén per origen el fet d'haver nascut en un lloc o la procedència familiar.

3. Com assenyalen Carrasco et al. (2005: 53): «La perspectiva que predomina en les anàlisis que es porten a terme sobre la integració dels infants i dels joves de la immigració estrangera és generalment adultocèntrica, etnocèntrica i sociocèntrica. Les perspectives del jovent són poc reconegudes i les valoracions que es fan sobre les condicions d'integració dels infants i joves d'origen immigrat estan molt sovint impregnades de prejudicis culturals i de classe defensats pels adults». 
general, la seva imatge s'ha modelat en relació amb la teoria del dèficit i amb idees de fracàs escolar, violència de les bandes i problemes d'adaptació, entre altres. Poques vegades s'ha elaborat a partir del reconeixement de capacitats $\mathrm{i}$ habilitats d'adaptació, acomodació i integració social i cultural.

A través de l'anàlisi dels relats biogràfics, la recerca fa un apropament als contextos i als condicionants que influeixen en els processos identitaris dels fills $\mathrm{i}$ les filles de famílies que han realitzat trajectòries i experiències de migració a la ciutat de Barcelona ${ }^{4}$. A l'Estat espanyol, la producció científica sobre joves d'origen immigrat és recent i s'ha centrat en problemàtiques sorgides al món escolar o també, en alguns casos, en l'estudi de les bandes llatines o, encara més recentment, en les condicions de vida, sense analitzar realment les dinàmiques identitàries en relació amb els contextos d'inclusió i/o exclusió social, ni a partir de joves que no pertanyen a cap grup o sector problematitzat a priori.

El contacte cultural, implícit en els moviments migratoris, genera canvis culturals en les persones migrades, però també en la societat receptora. S'estructuren identitats urbanes noves, conseqüència de relacions multiculturals que faciliten el coneixement intergrupal i, secundàriament, la cohesió i la convivència, però també es generen situacions conflictives de caràcter estructural, aprofitades per reconstruir discursos essencialistes que posen l'accent en la diferència cultural com a problema principal per conviure en harmonia i que justifiquen situacions de discriminació i exclusió social. D’aquesta manera, queden articulades les categories joves d'origen immigrat $\mathrm{i}$ risc de marginació $i$ discriminació. El risc social, resultat de barreres estructurals, afecta gran part d'aquests nois i noies. Variables relacionades amb l'educació, el mercat laboral, el territori, les relacions socials i les polítiques d'immigració actuen com a eixos d'exclusió social (Fangen, 2010; Fangen et al., 2010, 2012) i en dificulten la inclusió social com a ciutadans amb igualtat de drets.

La pregunta fonamental és «Quina identitat individual, social i etnocultural construeixen els fills de persones immigrades procedents de diferents contextos culturals, en una societat que estableix un model de relació multicultural asimètric i estructuralment desigual?». L'objectiu d'aquest article és descriure com es defineixen les identitats dels joves en relació amb els contextos de discriminació viscuts.

Els resultats de la recerca ${ }^{5}$ corroboren que, malgrat la vivència o la percepció de situacions de discriminació en les seves trajectòries de vida, els joves entrevistats construeixen una identitat flexible, dinàmica, oberta i múltiple gràcies a l'aprenentatge, la resistència i el procés d'adaptació. Es tracta d'identitats noves

4. La immigració estrangera que trobem a la ciutat de Barcelona és molt diversa en relació amb l'origen, el perfil migratori, els patrons d'assentament, els nivells formatius, els processos d'integració i les condicions de vida. Quant als fills i filles de famílies immigrades, també són un col-lectiu molt divers que comparteixen moltes característiques amb els joves nacionals parells.

5. En tractar-se d'una mostra estratègica no probabilística, els resultats no coincideixen amb els d'altres recerques revisades. En cap cas es vol extrapolar aquests resultats a la resta de fills i filles de famílies immigrades extracomunitàries. 
perquè sumen identificacions de la cultura familiar i de la cultura de la societat on estableixen relacions i vivències. Són identitats vinculades socialment en positiu. Fan aculturació i enculturació inclusives, que agreguen i engloben elements culturals diferenciats. Tenen una identitat flexible que els atorga capital cultural i social i que els posiciona amb avantatge en la societat multicultural actual, amb unes habilitats relacionals i de comunicació millors per interactuar amb altres joves i colllectius, com també per fer front a situacions d'adversitat que poden dificultar, en moments determinats, una inserció normalitzada a la societat. Són identitats que cerquen legitimitat a base de resistències i projectes.

Aquest article s'estructura en cinc apartats:

1. Visió general del context en què es produeix la recerca.

2. Revisió del marc teòric sobre identitat i discriminació en relació amb processos migratoris.

3. Plantejament metodològic.

4. Resultats.

5. Discussió.

Finalment, se'n presenten les conclusions més rellevants.

\section{Context}

Barcelona és una ciutat d'immigració des de fa dècades. Receptora inicial d'immigració interior, en els últims anys, ha viscut una arribada de població estrangera que hi ha generat canvis a nivell social, cultural, demogràfic i econòmic. Una de les característiques més importants és el gran pes de la immigració familiar.

Segons el Departament d'Estadística de l'Ajuntament de Barcelona, l'any 2011, la població estrangera era de 278.269 persones, és a dir, representava el $17,22 \%$ del total de població de la ciutat. Pel que fa a la procedència, el $39,77 \%$ dels estrangers residents a Barcelona són llatinoamericans; el 29,93\%, de la Unió Europea; el 21,39\%, asiàtics, i el 7,4\%, africans. Les nacionalitats principals són: la pakistanesa (un 7,95\%) ${ }^{6}$, la italiana (un 7,9\%) i l'equatoriana (un $6,49 \%)$, seguides de la xinesa $(5,4 \%)$, la boliviana $(5,3 \%)$, la peruana (5\%) i la marroquina (4,9\%). Els marroquins són els estrangers que fa més temps que hi són. Els joves estrangers de 15 a 29 anys representen el $31 \%$ del total de població d'aquesta edat, mentre que aquesta franja d'edat (nacionals i estrangers) representa el $16,57 \%$ del total de la població.

Malgrat que un nombre important de famílies i persones d'origen estranger han seguit un procés migratori amb èxit i que aquest fet reforça la idea d'heterogeneïtat dels diferents col-lectius, el cert és que, tot i no que no es pot establir una relació lineal entre pobresa i immigració extracomunitària, les dades de l'informe FOESSA 2008 indicaven que un nombre alt de famílies immigrades a Espanya es trobaven per sota el llindar de la pobresa. Les rendes

6. Percentatge respecte al total de la població estrangera al municipi. 
d'aquestes famílies eren inferiors a les de la població espanyola, amb diferències significatives. Les taxes de pobresa severa afectaven majoritàriament els estrangers no procedents de la Unió Europea, concretament un 20\% de les llars. Són nous pobres i se situen en els estrats més desfavorits de la societat. L'impacte que la crisi econòmica i social està tenint, des de l'any 2008, en les economies més precàries $\mathrm{i}$, per tant, en gran part dels col-lectius de persones immigrades de classe treballadora, empitjora substancialment aquesta realitat. Les fonts dels ministeris de Treball i Immigració, d'Interior i d'Educació assenyalen una disminució de l'arribada de nous immigrats i un augment dels retorns. L'atur, l'esgotament de les prestacions per aquest concepte i la impossibilitat de fer front a les hipoteques ha obligat moltes famílies a enviar els fills als països d'origen, a perdre els pisos acabats de comprar i a fer retorns temporals, sense acollir-se al pla de retorn del Govern per no perdre la targeta de residència. Per a moltes persones, la pèrdua de la feina ha comportat també la pèrdua del permís de residència i això ha provocat que quedessin en situació irregular. La crisi es manifesta especialment agressiva amb els joves que presenten taxes d'atur properes al 50\% (Fundación FOESSA, 2012). En aquests moments, és quan l'Europa Frontess esdevé una realitat, més que una metàfora, per als joves adults d'origen extracomunitari. Decreix la capacitat de l'estat del benestar i augmenten les forces i els discursos xenòfobs, l'estratificació social i la legitimació de l'exclusió social basada en elements culturals i ètnics. Les retòriques europees sobre ciutadania, diversitat ètnica i solidaritat incrementen la polarització i la segmentació social (Fangen et al., 2012).

És una realitat que immigració i discriminació són dues categories encreuades. La condició social dels pares es transmet als fills i a les filles, la mobilitat ascendent és difícil d'assolir en entorns desfavorits, es categoritza els joves com a subjectes en situació de vulnerabilitat i poques vegades es qüestionen les condicions estructurals de la societat, de manera que la responsabilitat recau en famílies i joves. Vist aquest context, podem afirmar que els fills i les filles de les famílies immigrades extracomunitàries poden viure situacions d'alt risc d'exclusió social que incidiran en les seves identitats, vinculacions i pertinences?

\section{Marc teòric}

La identitat és l'expressió de la identificació que fa la persona amb una manera d'entendre la vida, amb un conjunt de significats simbòlics i amb un tipus d'existència determinat. Les identitats són plurals, dinàmiques, diverses i canviants, i cada persona té moltes filiacions (Maalouf, 1999; Sen, 2007). La construcció de la identitat està guiada per les finalitats de la persona (Bauman, 2005), però la societat xarxa fa replantejar-ne la construcció (Castells, 1998). Les persones en contextos de multiculturalitat realitzen adaptació transcultural a través de processos d'aculturació (Rodrigo Alsina, 1999).

En aquesta recerca, s'hi proposa el concepte de flexibilitat identitària. Es tracta d'una flexibilitat o d'una variabilitat cultural que permet que els joves gaudeixin d'una acomodació cultural que en facilita la inclusió social, que 
s'identifiquin i que es vinculin amb elements de la cultura d'origen i de la cultura receptora, segons la situació i el context de cada moment. Un procés, però, carregat de contradiccions internes i dificultats externes. Esteva-Fabregat (1993: 19) refereix que moltes persones demostren una capacitat plàstica o adaptativa a diferents condicions ambientals que pot estar lligada a la pròpia personalitat i al context d'origen i d'arribada. La flexibilitat adaptativa dels pares (Esteva-Fabregat, 1993: 230), necessària per «sobreviure» en un entorn social i cultural difícil — i a vegades hostil—, guarda una relació directa i estreta amb la flexibilitat identitària dels fills.

El concepte d'inclusió és complex i diferenciat, i està interrelacionat amb condicions globals, nacionals i locals, com també amb condicions individuals i estructurals (Fangen et al., 2012: 202). La desigualtat inherent a les estructures socials i econòmiques no facilita que es compensin les situacions de desavantatge inicial, i la discriminació per origen actua com a eix de desigualtat destacat en moltes famílies immigrades. Inequitats de tot tipus funcionen com a determinants de les seves condicions de vida i són causa de la majoria de problemes que han d'afrontar. Per a molts joves, l'origen ètnic, visualitzat a través del nom o de l'aspecte físic, suposa situacions de discriminació i de risc d'entrar en un procés d'exclusió social.

Des de la perspectiva d'aquest context de desigualtat i risc, la identitat requereix una anàlisi interaccional i dinàmica, tenint en compte que és una estructura multidimensional $\mathrm{i}$ amb una dialèctica contínua entre la permanència i el procés evolutiu (Camilleri et al., 1990). Aquests autors destaquen que la coexistència de grups culturals diversos a França obliga a desplegar estratègies identitàries, amb la finalitat de moderar el conflicte de la persona que viu entre dues cultures i evitar el patiment derivat d'amenaces contra la identitat. La pobresa formativa i educacional, les dificultats lingüístiques i la pobresa cultural i material connecten facilment amb el conflicte social (Jazouli, 1995). D'altra banda, la concentració escolar i de població immigrada en espais restringits, junt amb la manca de sortides laborals per als joves i l'augment de la delinquiència, afavoreixen l'estigmatització dels barris i, paral-lelament, el qüestionament de les relacions interètniques i dels problemes interculturals subjacents (Rinaudo et al., 1995). La no integració en el món laboral pot portar molts joves a la radicalització de la seva identitat cultural (Baillet, 1999). Malgrat tot, Lepoutre (2001) assenyala que la identitat ètnica i cultural dels joves es reinventa i es reconstrueix a partir del model occidental, que difumina i dilueix elements identitaris de la cultura dels pares. Després de les revoltes de les banlieues l'any 2005, l'anàlisi de Castel (2007) posa èmfasi en les contradiccions d'un estat que pretén eliminar l'element ètnic com a diferenciador entre els ciutadans, però que, alhora, no és capaç d'establir els mecanismes necessaris per evitar la discriminació per origen.

Portes i Zhou (1993), Zhou (1997), Rumbault i Portes (2001) i Portes i Fernández Kelly $(2007,2008)$ proposen la teoria de l'assimilació segmentada, posant de manifest que predominen situacions socioeconòmiques precàries en gran part de les «segones generacions» de «color» i també en «terceres gene- 
racions», la qual cosa contribueix a desenvolupar subcultures adverses que atrapen i que segreguen les persones. Merenstein (2001) afirma que la jerarquia racial i els estereotips i el racisme existent en la societat nord-americana fan que moltes persones de grups minoritaris construeixin identitats negatives $\mathrm{i}$ conflictives que interioritzen; mentre que Pyke (2001) constata el gran pes que exerceix el racisme social sobre els grups minoritaris. També la classe social crea condicions estructurals de diferenciació ètnica i, per tant, influeix en els significats de la identitat (Lee, 2001). Suárez-Orozco (2003) entenen que les identitats i els estils d'adaptació estan interrelacionats amb el context i la imatge social construïda, mentre que Alba (2005) i Alba i Waters (2011) indiquen que els límits que s'estableixen entre el grup majoritari i els minoritaris porten a refermar les identitats d'aquests, limitades pels discursos, les representacions $\mathrm{i}$ les imatges atribuïdes pel grup majoritari (Song, 2003).

Els estudis teòrics i empírics realitzats a l'Estat espanyol mostren que els projectes migratoris dels pares condicionen pràctiques i imaginaris de fills $\mathrm{i}$ filles, tot i que no es poden fer discursos homogeneïtzadors ni estàtics sobre els processos d'integració i de construcció de la identitat (Torrabadella i Tejero, 2005). Aquestes autores assenyalen que cal qüestionar la problematització i els discursos alarmistes sobre la integració dels fills i les filles de famílies immigrades. Les seves identitats i pertinences es concreten en el model de pertinença doble o múltiple, de confusió, de mimetització i d'evasió imaginària (Massot, 2003), tenint en compte que la situació de biculturalitat $o$ pluriculturalitat suposa riquesa en l'aprenentatge de valors, llengües i cultura. Molts joves llatins viuen una experiència migratòria marcada per una forta enyorança, una adolescència viscuda en una família transnacional, sentiment de desarrelament, amb un retrobament emocionat $\mathrm{i}$ alhora traumàtic pel desconeixement del mitjà i dels pares (Feixa et al., 2006), mentre que Aparicio i Tornos (2006) observen una inserció no degradant ni conflictiva dels joves d'origen marroquí, peruà i dominicà. Tanmateix, per Delpino (2007), els joves llatinoamericans volen sentir-se diferents dels joves autòctons i viuen una època de crisi d'identitat. El reflex que molts d'aquests joves perceben d'ells mateixos no sempre és positiu, i això els genera vulnerabilitat personal i una lluita contra la manera com són percebuts i contra estereotips, fet que els comporta un gran desgast emocional en la construcció de la seva identitat. Pàmies (2008) fa referència a les dificultats de construcció identitària de nois i noies d'origen marroquí. Els que presenten fracàs escolar i pateixen més dificultats per inserir-se al mercat laboral es troben més allunyats de la comunitat d'origen i també de la religió. En canvi, els nois i noies amb èxit escolar tenen menys contactes interculturals i es reconeixen com a musulmans. Domínguez i Daza (2008) entenen que els itineraris educatius en origen dels joves arribats durant l'adolescència, com també les experiències educatives en la incorporació a l'escola a Catalunya d'infants i adolescents, són factors determinants en les trajectòries d'èxit o de fracàs. El procés migratori produeix transformacions importants en les relacions, els rols i les funcions de les famílies que influeixen en l'educació dels fills i les filles. Carrasco (2005) i Carras- 
co et al. (2009) indiquen que el manteniment de les relacions intraètniques genera capital social i facilita l'escolarització davant prejudicis i estereotips que jutgen equivocadament les estratègies educatives i socialitzadores de les famílies. Tot i que els objectius del sistema educatiu contemplen la igualtat d'oportunitats, la realitat mostra una reproducció de jerarquies socioculturals i una interpretació etnocèntrica i sociocèntrica de les diferències percebudes en termes de capacitats i d'interessos. Els discursos i les pràctiques tenen un alt component essencialista que es tradueix en desigualtats d'expectatives en relació amb l'origen ètnic, nacional, lingüístic i cultural (Carrasco, 2003, 2004; Carrasco et al., 2011a), amb processos de segregació dels fills i les filles de famílies immigrades (Gibson i Carrasco, 2009). A les dades d'educació especial d'alguns centres educatius, s'hi observa una sobrerepresentació d'alumnat procedent de nacionalitats altament estigmatitzades en relació amb l'èxit escolar (Carrasco i Pàmies, 2008). Des de la perspectiva del dèficit, del manteniment de fronteres interètniques visibles i de barreres ocultes del sistema educatiu, es presenten alguns col-lectius com a incompatibles amb l'èxit acadèmic i la integració social (Carrasco et al., 2011b), fet que pot influir negativament en la construcció de la identitat. Malgrat aquestes situacions i aquests condicionants, Portes i Aparicio (2009) indiquen que aproximadament la meitat dels joves enquestats a Madrid i Barcelona mai s'han sentit discriminats a l'Estat espanyol i solament un 5\% diu que n'ha estat repetidament.

Tot i que l'heterogeneïtat social i cultural de les societats complexes és un element afegit en el procés de construcció de la identitat cultural i ètnica que viuen els fills de famílies immigrades, la construcció no lineal sinó complexa i dialèctica, alimentada pel conflicte interètnic, amb un procés d'aculturació cap a la cultura majoritària que domina tots els àmbits de la vida, pot ajudar a configurar una estructura de personalitat amb fortes contradiccions i ambigüitats, però que pot tenir, també, tal com assenyala Esteva-Fabregat (1984: 48), unes qualitats importants de plasticitat que els permeten estar més capacitats per afrontar les relacions interètniques. És en aquest element de plasticitat que es proposa la teoria de la identitat flexible.

\section{Plantejament de la recerca}

\subsection{Hipòtesis}

Les aportacions teòriques revisades i l'anàlisi del context m'han permès formular les hipòtesis que han guiat la recerca empírica. La finalitat d'establir hipòtesis no és buscar verificacions o refutacions, sinó tenir una guia inicial que permeti ajustar i concretar el guió de la informació que es vol obtenir dels joves biografiats:

1. Els fills de persones immigrades procedents d'altres contextos culturals tenen tendència a construir una identitat cultural flexible (complexa, múltiple, etc.), en la qual s'articulen elements de la cultura d'origen i d'acollida, que els poden portar a no identificar-se plenament amb cap o bé a tenir unes habilitats 
i unes capacitats específiques per adaptar-se i acomodar-se a la cultura dels pares i a la cultura majoritària, segons les necessitats i el context.

2. La identificació cultural i social que fan els fills de persones immigrades està en relació directa amb el grau d'inclusió o exclusió que assoleixen a la societat receptora $\mathrm{i}$ a la identitat $\mathrm{i}$ el reconeixement que aquesta atorga.

\subsection{Objectius}

El problema que cal investigar té dos objectius principals que estan relacionats amb els dos conceptes fonamentals del treball:

1. Reconstruir els processos identitaris que elaboren els fills i les filles de persones immigrades procedents de contextos socioculturals diversos a la ciutat de Barcelona.

2. Analitzar les interaccions que es donen entre les experiències d'inclusió i exclusió social i els processos identitaris d'aquests joves.

\subsection{Metodologia i disseny de la recerca}

El problema de recerca que plantejo consisteix a descriure, conceptualitzar i explicar els processos de construcció identitària que es posen en marxa i les interaccions que es produeixen amb el context familiar, social, polític, econòmic i cultural en què viuen. D'altra banda, també busco indagar en les seves expectatives, valors i experiències per entendre quina relació s'estableix entre la persona i el context. Aquesta recerca és fenomenològica, de tipus qualitatiu, i la metodologia utilitzada es fonamenta en els relats biogràfics. L'univers d'estudi són els joves, fills i filles de persones immigrades extracomunitàries a la ciutat de Barcelona. Es tracta d'una mostra estratègica, no probabilística? Els criteris d'inclusió que s'han utilitzat són els següents: residència a la ciutat de Barcelona, origen extracomunitari de pare i mare, temps mínim de residència a Barcelona i/o a Catalunya de cinc anys, edat entre les $17 \mathrm{i}$ els 30 anys, indicadors socioeconòmics diferenciats i diversitat ètnica o procedència regional diversa.

La mostra està formada per 17 noies i 14 nois (vegeu les taules $1,2,3$ i 4$)^{8}$. L'accés als informants s'ha fet amb la tècnica de la bola de neu amb mostra de conveniència, i l'obtenció de les dades ha estat realitzada mitjançant entrevistes en profunditat, semiestructurades sobre les informacions del procés migratori

7. Per confeccionar la població, vaig delimitar marcs socioculturals preferents. Vaig cercar els joves a les associacions d'immigrats, als instituts d'ensenyament secundari, a les associacions de veïns i veïnes, entre els estudiants de la universitat, etc. A través del mètode de la bola de neu, en vaig poder seleccionar casos nous. Una de les limitacions de la mostra és la sobrerepresentació dels joves d'origen marroquí, tot i que cal assenyalar que es tracta d'un dels grups de joves amb més temps de residència a la ciutat, per sobre de llatinoamericans i pakistanesos. El treball de camp l'he realitzat amb els joves seleccionats durant un any i mig (anys 2007-2008).

8. A les taules, s'hi han conservat les paraules emprades pels joves entrevistats. 
familiar, dades sociològiques, econòmiques i culturals de la família i dels joves, com també àmbits temàtics per interrogants i hipòtesis, oberts, semiestructurats i estructurats. Per poder analitzar sistemàticament les dades, he seguit el procés següent:

1. Lectura i anàlisi de les entrevistes amb identificació i selecció de fragments significatius de les narratives i les informacions.

2. Definició de les generalitzacions empíriques més rellevants de cada apartat.

3. Contrast de les teories i dels autors amb les generalitzacions empíriques corresponents a cadascuna de les hipòtesis principals que actuen com a categories d'anàlisi.

4. Contrast específic de narratives i d'informacions que convergeixen i que divergeixen amb les teories i les generalitzacions empíriques i que donen suport a les hipòtesis o les contradiuen.

\section{Identitats flexibles i discriminació}

\subsection{Sobre les identitats flexibles: "Sempre dic que sóc fill del Marroc, adoptat per Espanya i amb sentiment català. Això és el que em defineix»}

Tal com posa de manifest aquesta frase, les reflexions dels joves entrevistats, fetes des de la perspectiva que dóna cada trajectòria vital, corroboren la hipòtesi 1. Efectivament, es tracta de nois i noies amb identitats flexibles i múltiples, complexes, com ha de ser en una societat que ho és creixentment, i que es construeixen des de la barreja i la mixtura present a les societats actuals. Són identitats positives «amb dues cultures». No reneguen de l'origen ètnic ni de la societat on creixen i es desenvolupen com a persones, amb la qual cosa estableixen graus diferents de vinculació i pertinença.

"Jo he fet un procés. He nascut al meu país d'origen i després he estat adoptat per aquesta societat. Tinc un sentiment per aquesta societat també. És on visc i on viuré els propers anys. Me l'he fet meva», diu Omar.

De manera circumstancial i contextual, la identitat es va modificant a mesura que s'elaboren estratègies d'adaptació. «Yo antes era una persona muy machista. Ahora no es que no lo sea, pero soy más tolerante, creo que aún tengo que corregirlo. Allá muchas mujeres sufren y no estoy de acuerdo", explica Juan Pablo, que va migrar en l'edat adolescent i que, tot i que s'identifica com a llatí, considera necessari que la persona nouvinguda s'adapti i s'integri a la societat d'acollida. Com s'ha verificat en diferents estudis, i jo mateixa he pogut comprovar, el temps en què es realitza el procés migratori és un factor rellevant. Així, trobem que els nois i les noies arribats durant l'adolescència viuen aquest moment de la seva trajectòria vital de manera conflictiva i problemàtica, en relació amb els canvis, els trencaments i les pèrdues. No obstant això, també és cert que les capacitats d'acomodació i d'adaptació són destacables $i$ es posen en marxa ràpidament.

La identificació cultural dels joves entrevistats està influïda pel context familiar, per les interaccions quotidianes (Pujadas, 1993), per les relacions 
socials amb els iguals, per les pautes i els patrons de la cultura d'origen i de destinacio, per les imatges socials construïdes del grup d'origen, per les oportunitats i per les trajectòries d'èxit o de fracàs escolar i/o professional. Prenen com a referents els elements que consideren més positius de la cultura familiar i de la cultura de la societat on creixen. No es tracta de renúncies, sinó d'incorporacions per sumar i enriquir. Es produeix una adaptació transcultural (Kim, 1991, a Rodrigo Alsina, 1999) a partir del coneixement i la vivència de la nova societat, i manifesten que la distància cultural és menor de la que de vegades es vol demostrar.

Podem parlar d'identitat múltiple en gairebé tots els nois i noies, que, de manera més rellevant, s'evidencia en els joves d'origen musulmà, ja que es refereixen a la seva identitat com a musulmans, marroquins (o pakistanesos) i catalans. Per exemple, Said, amb procés migratori en edat infantil i definit per un trànsit i una adaptació ràpids, diu: «Sóc musulmà, però més català. Més musulmà que pakistanès. Pakistanès, molt poc. No espanyol, català. $70 \%$ català i 30\% musulmà».

La identitat d'aquests joves es construeix en el canvi i és, per tant, mòbil, dinàmica, adaptativa i fluida (Juliano, 1998). Fan ús d'estratègies identitàries (Camilleri et al., 1990) per adaptar-se a les situacions que van sorgint al llarg de la infancia, l'adolescència i la joventut. Alguns d'aquests joves desenvolupen estratègies de resistència davant el sentiment que el país i la cultura d'origen estan desvalorats. La identitat d'origen no queda diluïda i es reconstrueix des del model occidental (Lepoutre, 2001). La frase que dóna resposta a la hipòtesi, «Sempre dic que sóc fill del Marroc, adoptat per Espanya i amb sentiment català. Això és el que em defineix», és ben significativa del canvi identitari que es va produint (Barth, 1976), de la mixtura i barreja cultural (Song, 2003), de les competències interculturals d'aquests joves i de la capacitat d'adaptació a contextos canviats (Eriksen, 1993). Malgrat els dèficits integradors de la societat receptora, els nois i noies biografiats expressen un sentiment de pertinença i d'arrelament positiu que no sempre es correspon amb una resposta social o institucional inclusora. No reneguen de la identitat lligada a la destinació, sinó que volen fer-la seva. D'altra banda, es manté la vinculació amb origen que els deixa una forta empremta. Les identitats que refereixen els joves es fan i són segons el lloc de naixement, les relacions, la filiació ètnica, els sentiments, les emocions i el reconeixement social. Són identitats riques en valors i elements culturals (Massot, 2003), però no negatives ni conflictives (Merenstein, 2001). Cap dels joves biografiats es tanca en una sola identitat. Fins i tot aquells que es defineixen com a exclusivament de la cultura d'origen o de destinació admeten que en ells hi ha una part important de l'altre referent. Tenen identitats múltiples que són una compilació de referents diversos. Aquests nois i noies s'identifiquen amb el sentiment transnacional que atorga el fet d'haver viscut un procés migratori entre països i cultures diferenciats. La percepció inicial de viure «entre dos mons» es converteix en un viure «amb dues cultures». En el relat de Virginia es posa de manifest que el canvi i la flexibilitat identitària segueixen un procés gradual: 
Por ejemplo... ¿Cómo te lo explico? Yo vivo aquí y yo me siento bien aquí y... Estoy adaptada, y hay costumbres que ya las he cogido de aquí también. Y esto me une más a aquí. Y allá también, pero ya no es lo mismo. Tu corazón siempre va a estar con tu país, pero, poco a poco, dejas las costumbres de allí.

\subsection{Sobre discriminacions, dificultats d'inclusió i risc d'exclusió: "Quan ets invisible, pots exercir la normalitat"}

Tot i l'evidència que la discriminació negativa, per origen, que pateixen molts joves és una pràctica repetida que s'inscriu en una realitat amb comportaments carregats de prejudicis i estereotips classistes, amb components xenòfobs i racistes greus, així com reproductora de desigualtats, la hipòtesi 2 no queda corroborada. Els joves entrevistats són conscients d'aquests prejudicis i estereotips, dels quals sovint són víctimes. Creuen que el racisme és present a la societat i que afavoreix actituds negatives que els estigmatitzen i els afecten (Lepoutre, 2001; Pyke, 2001), a més a més, viuen en pròpia pell les actituds diferenciades i jeràrquiques envers els diversos col-lectius de persones immigrades. Aquestes situacions de discriminació no generen canvis en les identitats ni en les pertinences dels joves entrevistats, però sí en sentiments i vinculacions, la qual cosa converteix els joves en crítics del sistema social, encara que sense tancar-se ni radicalitzar la identitat d'origen (Baillet, 1999), ni reforçar-la (Song, 2003). Les seves narratives combinen vivència personal $i$ anàlisi social, $i$ es mostren com a veritables observadors socials privilegiats des d'una òptica d'actors implicats en el context.

Les veus i els discursos dels nostres joves manifesten les seves opinions clarament. És el cas de Hassan, que és molt crític amb l'actitud de la societat envers les persones immigrades extracomunitàries. Creu que, a la base de la discriminació, hi ha un component de classe social. Pensa que la societat confon el significat de la paraula integració i que la majoria de prejudicis i estereotips neixen del desconeixement d'unes persones vers les altres, fet que potencia preferències i jerarquitzacions. Tanmateix, alguns joves, com ara César, també són crítics amb els seus coètnics. Diu que tenen un comportament erroni, en part perquè els pares els tenen consentits i obtenen tot allò que desitgen: «Hay muchos que se hacen pandilleros, otros no quieren trabajar, solo quieren ir siempre de fiesta (pequeño silencio), no sé, claro, es que se está comenzando a crear un cambio de vida ahora».

Bilal s'ha sentit discriminat moltes vegades:

Moltíssimes. Des d'agafar un taxi com et deia abans, a anar a un bar..., a una discoteca, no tant. Mirar-te malament. Anar a una entrevista de treball, dir el nom i quedar-se en un silenci que et talla... I haver de dir: «No, no, que jo he nascut aquí». I això passa en l'actualitat [...] A veure, m'he sentit ben tractat, però t'has de fer respectar. Quan vaig fer la mili, em vaig trobar gent que em deia "Jo no sóc racista, però els moros no els puc veure, però tu em caus bé». És dur sentir això. 
Malgrat aquestes situacions de desavantatge, de les seves narratives, s'infereix que la predisposició per la inclusió i la integració social és determinant en l'evitació dels processos que portarien a segregació i exclusió social aquells que pateixen les situacions de més vulnerabilitat. María assenyala que, malgrat les dificultats viscudes, no se sent exclosa i sempre ha tingut clar que no l’afectarien les circumstàncies més difícils:

D'exclosa, no me'n sento per res, perquè jo ja he intentat no excloure'm. En algun moment de la teva vida, quan ets adolescent i no saps gaire bé per on tirar, doncs, potser, que és el que em va passar a mi, potser t'ajuntes amb gent amb qui tu et sents identificada, que són negres. Però després penses i, quan madures una mica, dius: «A veure si m'empaqueto jo mateixa, si em tanco doncs no arribaré a ningun lloc». I jo tinc papers i he nascut aquí, o sigui, jo tinc les mateixes possibilitats que té qualsevol persona. Llavors, em sento com una persona normal que està estudiant $i$ treballant.

Enfront dels discursos i de les pràctiques xenòfobes i racistes, mostren una incansable voluntat per ser uns més de la societat, amb les particularitats ètniques i culturals pròpies, i lluiten per sortir endavant.

En el discurs dels nois i noies, hi trobem unes expectatives de futur compartides. Tenen un imaginari carregat d'il.lusions i de projectes que xoca amb algunes frustracions i decepcions ja experimentades. Dels relats, se'n desprèn una gran predisposició a la integració social vinculada a estratègies de mobilitat ascendent (Rumbault i Portes, 2001; Portes i Fernández Kelly, 2007). Lluny de desmotivar-se, els joves entrevistats demostren una gran predisposició a formar part de l'entorn i sentir-s'hi arrelats. No mostren rebuig cap a la societat que els discrimina. N'hi ha alguns que ho viuen com a fets puntuals, fruit del desconeixement dels autòctons cap a les persones immigrades, i d'altres que s'hi esforcen per fer-hi front. S'evidencia una necessitat d'autoafirmació (Song, 2003).

Majoritàriament, aquests nois i noies consideren que la societat catalana és inclusiva, malgrat que hi identifiquen dispositius d'exclusió social. Afirmen que es produeix discriminació amb les persones immigrades per raons econòmiques i d'origen. Un fet que cal destacar-ne és que els joves relacionen classe social i origen en l'anàlisi que fan. D'una banda, asseguren que la societat receptora prefereix les persones estrangeres amb alt poder adquisitiu enfront de les que són immigrades de classe social treballadora. Quant a l'origen, tots mostren una visió força homogènia i coincident. Entenen que es jerarquitza, de manera que s'estableixen diferències i preferències vers uns col-lectius respecte a uns altres. En aquest sentit, indiquen que hi ha més discriminació vers els procedents de països musulmans. Consideren que la societat prefereix les persones sud-americanes abans que les africanes o asiàtiques, i afirmen que la societat, les polítiques i les lleis afavoreixen les procedents dels països de l'Amèrica Llatina. Tot i aquesta crítica negativa de les pràctiques socials i polítiques, estan convençuts que aquí viuen millor. Quan ho comparen amb el país d'origen, aquest sempre rep crítiques relatives a les desigualtats socials i a les pràctiques econòmiques, polítiques i jurídiques més injustes. 
Les narratives dels joves permeten fer unes consideracions globals sobre la seva realitat en la societat catalana. La més important és que el procés d'adaptació i d'inclusió social és positiu i satisfactori per a la majoria de famílies, malgrat les dificultats i els entrebancs de tipus laboral, jurídic, econòmic i social. Mostren una gran maduresa i construeixen identitats fermes i coherents que els permeten vèncer els obstacles i les hostilitats que tots pateixen en una mesura més o menys elevada. És cert que, en alguns casos, la discriminació negativa és viscuda molt malament, la qual cosa afecta anímicament els joves i les seves famílies, però també es verifica que demostren una gran capacitat de superació i reafirmació personal. Alguns busquen la diferència per posicionarse de manera singular en la societat, uns altres volen ser una persona més de l'entramat social i passar desapercebuts, perquè, tal com diu Omar: "Quan ets invisible, pots exercir la normalitat», i això evita un reconeixement estigmatitzador.

\section{Processos de construcció identitària. Una proposta de classificació}

La identitat flexible que mostren aquests joves la construeixen els propis subjectes en la cruilla cultural, com a resultat de la mixtura de cosmovisions (Song, 2003) i la capacitat adaptativa de les persones i de la pròpia identitat (Phinney, 1993, a Labrador Fernández, 2001). És una compilació de les dimensions cultural, social, etniconacional i religiosa. Són identitats dinàmiques que viuen canvis com a resultat de cada etapa vital, de les pràctiques de socialització, de les dinàmiques relacionals (Heider, 1958, a Camilleri et al., 1990: 14) i de les estratègies que es posen en joc per maximitzar avantatges (Camilleri et al., 1990), afrontar dubtes existencials i situacions de dificultat i resoldre'ls. En alguns casos, apareix una confusió identitària que reflecteix la perspectiva processual i canviant, perquè la identitat es va elaborant amb les experiències i les vivències quotidianes $i$ es modifica a través d'elles. El context, com assenyala Benhabib (2000), i els processos històrics i socials (Mead, 1934, a Camilleri et al., 1990: 14) també hi tenen un paper fonamental.

No som davant de joves amb identitats conformistes ni silenciades. Són identitats resistents (Torrabadella i Tejero, 2005), perquè els joves volen ser actors socials i són identitats amb projectes en la mesura que tenen expectatives de creixement personal i de futur (Castells, 1998). Fan identitat d'oposició quan perceben que la d'origen és amenaçada i identitat d'apropament perquè reivindiquen la seva pertinença a la comunitat de manera oberta i clara. L'oposició i l'apropament configuren els eixos de la flexibilitat de què es dota la identitat dels joves biografiats, que són capaços de reconciliar, encaixar i afrontar diverses cultures i realitats, amb la qual cosa mostren una competència transcultural fonamental per a la societat del futur (Kim, 1998, a Rodrigo Alsina, 1999). Així doncs, la construcció identitària dels joves sorgits de la migració té un caràcter dinàmic i es va desenvolupant en una cruilla o intersecció cultural on conflueixen cosmovisions múltiples que afavoreixen la flexibilitat identitària. No presenten assimilació plena, perquè la força dels valors i dels 
llaços afectius transmesos pels pares mantenen un fort capital ètnic (Modood, a Alba i Waters, 2011). A diferència de les tesis apuntades per Berry et al. (2006), el seu perfil ètnic evidencia una bona adaptació psicològica i sociocultural, sense afectació important per les discriminacions experimentades.

Malgrat que no és facil definir la identitat ni els sentiments de pertinença (Weller, 2011), els resultats de la recerca corroboren que la identitat que construeixen tots els joves entrevistats és flexible gràcies a l'aprenentatge, la resistència i el procés d'adaptació, influïts pels factors d'inclusió i/o d'exclusió que van sorgint al llarg del recorregut vital. Es tracta d'identitats noves perquè sumen identificacions de la cultura familiar i de la cultura de la societat on estableixen relacions i vivències. Fan acomodació sense assimilació (Gibson, 1988), perquè s'adapten a la societat sense perdre els referents de l'origen familiar. Per tant, des de la perspectiva cultural, ni són com els pares ni com els joves autòctons parells, sinó la suma d'uns i altres. Tots els joves expressen, en una mesura més o menys elevada, que volen compartir el llegat dels pares amb els elements socioculturals de la societat on viuen. Els nois i noies amb identitats flexibles són navegadors culturals (Carter, 2005) que poden actuar de pont entre la diversitat de col-lectius, si es disposa dels recursos i de les eines necessaris. Es nodreixen d'una multiplicitat i d'una gran diversitat de patrons, valors, creences i pautes culturals que els donen una amplitud de mira i una obertura en totes direccions. Les identitats culturals flexibles capaciten per al diàleg i la comprensió de les «altres» pràctiques culturals. Són identitats dinàmiques que es construeixen de forma diacrònica, en la interacció entre el «nosaltres» i els «altres", de caràcter estructural i de tipus multidimensional (Camilleri et al., 1990). La flexibilitat identitària permet desenvolupar de manera integrada la cultura dels pares i la cultura de la societat majoritària, amb la qual cosa construeixen una identitat més rica que la dels joves autòctons, ja que desenvolupen capacitats i competències de plasticitat (Esteva-Fabregat, 1984) que els permeten viure totes dues cultures sense conflictes interns ni externs negatius o que, en qualsevol cas, poden esdevenir conflictes de creixement personal. No considero que aquests joves estiguin a la defensiva per escapar de l'angoixa que els produeix el fet d'estar entre modernitat i tradició. Són capaços de viure-les totes dues de manera harmoniosa, a través d'un procés d'adaptació i acomodació lent, gradual, carregat de dificultats però eficaç.

La majoria dels joves entrevistats relaten experiències a l'escola, al món laboral o a nivell social que, si bé no es poden qualificar d'exclusores, els han dificultat moments importants dels seus cicles vitals. Evidentment, els seus recorreguts, contextos i experiències de vida no són ni de bon tros equiparables als dels joves que segueixen un procés migratori personal, els més vulnerables en termes d'exclusió social (Fangen et al., 2012: 206). Els fills i filles de famílies immigrades parteixen amb avantatges respecte a aquests, però viuen en handicap comparatiu amb els parells autòctons, perquè l'estructura d'oportunitats no és la mateixa. L'aixopluc familiar protegeix i evita que les experiències discriminatòries comportin un risc social immediat, però sumen i condicionen vinculacions i sentiments de pertinença $i$, amb el pas del temps, poden negati- 
vitzar les actituds. Sembla, però, que l'arrelament social que es va teixint amb el pas dels anys actua de protecció contra identitats tancades i oposades.

Cada història personal i les trajectòries migratòries i de vida són diferents, però els relats biogràfics ens permeten observar tendències recurrents que posen de manifest característiques similars entre alguns nois i noies. Aquestes similituds permeten agrupar els joves en quatre categories tipus, amb la finalitat d'analitzar-les i d'entendre-les de forma focalitzada, i alhora comparativa, per poder establir relacions de causa-efecte entre les identitats i les situacions de discriminació viscudes. L'adscripció a aquestes categories pot ser circumstancial i canviant segons el moment de la trajectòria de vida. Els tipus identificats són els següents:

1. Joves amb una identitat cultural i ètnica flexible, amb més vinculació amb el context social i cultural majoritari, associat a una socialització i a una enculturació al país de destinació llargues i a un escàs sentiment de pertinença a la cultura d'origen relacionat amb trajectòries d'èxit escolar i laboral, que comparteixen algunes de les característiques següents (taula 1):

- Els joves entrevistats que podem incloure en aquesta tipologia són 2 nois i 6 noies. Presenten un llarg procés d'enculturació i socialització al país de destinació, amb enculturació i aculturació additiva i implicativa.

- Famílies amb adaptació i aculturació positiva, sense dificultats destacables ni problemàtiques de discriminació al treball, a l'habitatge o en les relacions socials que hagin complicat la seva inclusió i integració. Conflictes entre pares i fills per discrepàncies generacionals. Situació jurídica familiar estable, amb nacionalitat espanyola. Rols de gènere menys rígids i oposats que als països d'origen.

— Trajectòries escolars d'èxit sense vivències importants de discriminació i amb expectatives de continuar estudis. Experiències socials no discriminatòries. Tots els joves que treballen viuen el món laboral sense discriminació. L'origen ètnic no ha actuat en cap cas com a factor de segregació, discriminació o exclusió del mercat laboral. No són trajectòries llargues i, per tant, no han tingut gaires experiències en empreses diferents, però les que han tingut no han estat negatives.

- Tots parlen en castellà i el català resta com a segona llengua. En el cas dels procedents de l'Amèrica del Sud, se n'explica l'ús perquè és la llengua familiar. A les llars d'origen marroquí o pakistanès, la llengua materna es barreja amb el castellà i poques vegades amb el català. L'escolarització en català ajuda que tots el parlin sense dificultat $\mathrm{i}$, com expressa algun jove, cada vegada li donin més valor. L'ús del català el viuen com un vincle d'apropament al país de destinació, el consideren una llengua que els facilita l'establiment de relacions socials i que els configura una identitat.

- No fan endogàmia relacional de base ètnica. En general, no mostren afinitat per joves coètnics acabats d'arribar ni preferència per tenir una parella coètnica. Solament cataloguen com a coètnics els acabats d'arribar. Alguns joves emfasitzen la facilitat i la voluntat per establir relacions amb nois i noies 
de qualsevol procedència, sempre que no siguin del país d'origen, els quals rebutgen perquè els troben excessivament diferents. La no-identificació amb els joves coètnics es pot entendre pel fet que les trajectòries escolars d'aquests joves han generat una majoria de relacions amb infants autòctons, que han continuat durant l'adolescència i la joventut. També es pot explicar com a estratègia d'autoexclusió (ètnica) per evitar l'estigmatització. N'hi ha hagut pocs que hagin establert relacions posteriors amb joves acabats d'immigrar, excepte en aquells casos en què els espais de relació (associacions, casals, etc.) ho faciliten. Podríem dir que estem davant de processos d'apropament als joves autòctons perquè ells també se'n consideren i d'evitament de base ètnica, no expressament desitjats ni volguts. Són les dinàmiques relacionals les que ho determinen, més que no pas la voluntat per si sola.

- Posicionament en la classe treballadora i la classe mitjana assalariada. Situats ideològicament a l'esquerra. Crítics amb el sistema social, polític i econòmic.

- Un dels factors que més es repeteix i que incideix directament en aquesta tipologia és que cap dels joves s'ha sentit discriminat socialment, excepte en situacions molt puntuals. En cap cas consideren que la societat els discrimini, per contra, se senten ben tractats arreu i relativitzen les situacions viscudes, sense generalitzar. Això no exclou que siguin crítics amb el sistema i vegin situacions de discriminació social, econòmica i política al seu voltant envers altres persones que hagin seguit un procés migratori.

2. Identitat cultural i ètnica flexible, amb vinculació amb el context social i cultural majoritari, però amb més vinculació emocional i de pertinença a la cultura d'origen, associat a socialització i enculturació en origen, sense percepció de discriminació escolar i/o laboral en les trajectòries que segueixen. En síntesi, podem dir que, majoritàriament, aquests joves presenten les característiques següents (taula 2):

- Es tracta de 6 nois i 5 noies, cap dels quals no ha nascut al país de destinació, que, excepte els tres joves arribats durant la infancia, han seguit un procés llarg de socialització i enculturació al país d'origen.

- Procés migratori familiar difícil amb ús de xarxes familiars. Pluralitat de situacions jurídiques familiars i personals. Rols de gènere menys rígids i oposats que al país d'origen.

- Aquest grup es destaca per una forta vinculació amb el país d'origen, sobretot els arribats amb més edat, i el mite del retorn present. Les noies llatines s’identifiquen més com a tals i els marroquins manifesten un vincle més fort amb Catalunya.

- Han seguit trajectòries escolars diverses, amb un nombre important de joves que han completat estudis de secundària i que han seguit amb formació professional. En algun cas, han vist truncades les trajectòries escolars iniciades al país d'origen. Pràctiques laborals diverses pel que fa a les condicions de treball $\mathrm{i}$ amb expectatives que els estudis els ajudin a millorar. 
Taula 1. Comparativa de nois i noies entrevistats

\begin{tabular}{|c|c|c|c|c|}
\hline \multicolumn{3}{|c|}{ Dades personals } & \multicolumn{2}{|r|}{ Dades sociodemogràfiques } \\
\hline Nom & $\begin{array}{l}\text { Edat, } \\
\text { lloc de naixement o d'origen, } \\
\text { anys de residència }\end{array}$ & $\begin{array}{l}\text { Parella } \\
\text { Emancipació }\end{array}$ & Formació i treball & $\begin{array}{l}\text { Xarxes socials } \\
\text { Ubicació ideològica }\end{array}$ \\
\hline Abel & $\begin{array}{l}21 \\
\text { Perú } \\
12\end{array}$ & $\begin{array}{l}\text { Viu amb els pares } \\
\text { i la germana. No parella. }\end{array}$ & $\begin{array}{l}\text { Universitària (en curs). } \\
\text { No treballa. }\end{array}$ & $\begin{array}{l}\text { Tots els amics són autòctons. } \\
\text { No té amics de fora, solament } \\
\text { un és peruà, acabat de conèi- } \\
\text { xer. Nacionalista de centre. } \\
\text { Classe treballadora. }\end{array}$ \\
\hline Said & $\begin{array}{l}21 \\
\text { Pakistan } \\
11\end{array}$ & $\begin{array}{l}\text { Viu amb els pares } \\
\text { i la germana. No parella. }\end{array}$ & $\begin{array}{l}\text { Fins a quart d'ESO. } \\
\text { Treballa al restaurant } \\
\text { familiar. }\end{array}$ & $\begin{array}{l}\text { Els amics són catalans, de } \\
\text { l'institut. Esquerra. Classe } \\
\text { mitjana propietària. }\end{array}$ \\
\hline Katy & $\begin{array}{l}20 \\
\text { Perú } \\
14\end{array}$ & $\begin{array}{l}\text { Viu amb la mare i els } \\
\text { germans. No parella. } \\
\text { Prefereix parella } \\
\text { autòctona } \\
\text { (pel masclisme). }\end{array}$ & $\begin{array}{l}\text { Universitat (en curs). } \\
\text { Treballs diversos, } \\
\text { temporals. }\end{array}$ & $\begin{array}{l}\text { Tots els amics són autòctons, } \\
\text { companys d'escola i d'institut. } \\
\text { Esquerra. Classe treballadora. }\end{array}$ \\
\hline Rajae & $\begin{array}{l}23 \\
\text { Marroc } \\
23\end{array}$ & $\begin{array}{l}\text { Viu amb els pares } \\
\text { i els germans. Parella } \\
\text { de Tunísia, sense } \\
\text { preferències. }\end{array}$ & $\begin{array}{l}\text { Universitat (en curs). } \\
\text { Treballa els caps } \\
\text { de setmana i en un } \\
\text { menjador escolar. }\end{array}$ & $\begin{array}{l}\text { De tot arreu: internacionals, } \\
\text { especialment catalans. } \\
\text { Esquerra. Classe mitjana } \\
\text { assalariada. }\end{array}$ \\
\hline Mercedes & $\begin{array}{l}21 \\
\text { Perú } \\
18\end{array}$ & $\begin{array}{l}\text { Viu amb la mare i l'àvia. } \\
\text { No té parella. Prefereix } \\
\text { que no sigui d'origen } \\
\text { peruà. }\end{array}$ & $\begin{array}{l}\text { Quart d'ESO. Batxillerat } \\
\text { (en curs). Li agradaria } \\
\text { fer INEF. Treballa al } \\
\text { sector del comerç. }\end{array}$ & $\begin{array}{l}\text { Té amics de tot arreu, del } \\
\text { Marroc, de l'Amèrica Llatina, } \\
\text { catalans. No es relaciona amb } \\
\text { peruans. Esquerra. Classe } \\
\text { treballadora. }\end{array}$ \\
\hline Lilian & $\begin{array}{l}23 \\
\text { Perú } \\
15\end{array}$ & $\begin{array}{l}\text { Viu amb els pares } \\
\text { i un germà més petit. }\end{array}$ & $\begin{array}{l}\text { Batxillerat. FP grau } \\
\text { superior de farmàcia. } \\
\text { Treballa d'auxiliar } \\
\text { de farmàcia. }\end{array}$ & $\begin{array}{l}\text { Amics catalans de pares } \\
\text { andalusos. No manifesta posi- } \\
\text { cionament ideològic. Classe } \\
\text { mitjana assalariada. }\end{array}$ \\
\hline Layla-2 & $\begin{array}{l}24 \\
\text { Barcelona (Marroc) } \\
24\end{array}$ & $\begin{array}{l}\text { Viu amb els pares i els dos } \\
\text { germans. Acualment no té } \\
\text { parella. Ha tingut parella } \\
\text { del Marroc que va conèixer } \\
\text { a Barcelona. Preferència } \\
\text { per parella d'origen } \\
\text { marroquí. }\end{array}$ & $\begin{array}{l}\text { ESO i àrab. FP grau } \\
\text { mitjà de turisme } \\
\text { (en curs). Treballa } \\
\text { a la botiga d'un } \\
\text { consolat a Barcelona. }\end{array}$ & $\begin{array}{l}\text { Amics de tot arreu. Té relació } \\
\text { amb molts joves en una } \\
\text { entitat d'immigrats d'origen } \\
\text { musulmà on col·labora. Dreta. } \\
\text { Classe treballadora. }\end{array}$ \\
\hline Vanesa & $\begin{array}{l}19 \\
\text { Barcelona (Filipines) } \\
19\end{array}$ & $\begin{array}{l}\text { Viu amb els pares i } \\
\text { un germà. No té parella. } \\
\text { No preferències. }\end{array}$ & $\begin{array}{l}\text { Universitària (en curs). } \\
\text { No treballa. Feina } \\
\text { temporal a l'estiu. }\end{array}$ & $\begin{array}{l}\text { Els amics són tots autòctons. } \\
\text { No es posiciona ideolò- } \\
\text { gicament. Classe mitjana } \\
\text { assalariada. }\end{array}$ \\
\hline
\end{tabular}


Taula 1. (continuació)

\begin{tabular}{ll} 
Situació jurídica & Discriminació \\
\hline oble nacionalitat. & No ha tingut problemes \\
& de discriminació. Considera \\
& que la societat jerarquitza \\
& els col·lectius.
\end{tabular}

Permís de residència i pendent de la nacionalitat ja tramitada.

Nacionalitat espanyola, amb renúncia a la peruana.

Nacionalitat.

Nacionalitat.

Doble nacionalitat.

Nacionalitat.

Nacionalitat.
Ha tingut les mateixes oportunitats. Mai s'ha sentit discriminat: «Potser a vegades m'han dit "moro", però molt poc. Mai la gent jove».

Se sent ben tractada aquí. No s'ha sentit discriminada. Considera que es discrimina per origen i que els col-lectius en situació pitjor són els marroquins i els pakistanesos.

No ha tingut problemes. Sensació d'haver gaudit de les mateixes oportunitats. Creu que la societat discrimina i jerarquitza els col-lectius d'immigrants.

Problemes al col-legi amb els companys, però diu que ha tingut les mateixes oportunitats i que no se sent discriminada. col-legi. Opina que es discrimina molta gent immigrada, però diu que ha tingut les mateixes oportunitats i que no se sent discriminada.

Mai no s'ha sentit discriminada. Opina que, en general, la societat no vol els immigrats magribins i que també s'estableixen prioritats entre els sud-americans (es prefereix els argentins).

En general, no s'ha sentit discriminada, excepte quan ha patit problemes puntuals amb algun company de l'escola.
Problemes amb un professor al

\section{Dades socioculurals}

Definició identitat

\section{i pertinença}

Identificació amb coetnics

Entremig. No se sent ni català

ni peruà, però la seva cultura

és d'aquí. El cos d'allà i la cultura

d'aquí. S'identifica més amb

Espanya que amb Catalunya.

Més català. $70 \%$ català i 30\% musulmà. Pakistanès molt poc, ni espanyol. Cap identificació amb els coètnics.

Catalana i peruana, però se sent més d'aquí que d'allà. S'identifica amb els coètnics amb anys de residència, amb els acabats d'arribar, no.

Cultura catalana, grup ètnic àrab: «M'identifico amb les noies estudiants».

No s'identifica amb cap element identitari. Només amb ella mateixa. Se sent de cultura catalana. No s'identifica gens amb els coètnics. Els veu molt diferents.

Llatina. En un punt entremig. La ment i l'educació és d'aquí, però amb fort lligam afectiu amb Perú. Sentiment d'espanyolitat. No s'identifica gens amb els coètnics. Se sent estranya. Identitat mixta. Barreja de dues cultures. Nació: catalana. Cultura: barreja. Grup ètnic: marroquí. Considera que els seus coètnics són els joves d'origen marroquí nascuts a Barcelona 0 que han viscut sempre aquí. Amb la resta, no s'hi identifica.

Mig catalana i mig filipina. Nació: Catalunya. Grup ètnic: català. Cultura: mig de cada. No s'identifica amb tots els coètnics. Els veu molt diferents d'ella.
Llengua

Castellà i català.

Català i castellà amb els amics, i de tot a casa.

A casa, castellà i amb els amics, català.

Amb els amics, castellà i català.

Més el castellà i també català.

Castellà amb els amics i català al treball.

Castellà 0 àrab. També català.

Castellà i poc català. 
Taula 2. Comparativa de nois i noies entrevistats

\begin{tabular}{|c|c|c|c|c|}
\hline \multicolumn{3}{|c|}{ Dades personals } & \multicolumn{2}{|c|}{ Dades sociodemogràfiques } \\
\hline Nom & $\begin{array}{l}\text { Edat, } \\
\text { lloc de naixement o d'origen, } \\
\text { anys de residència }\end{array}$ & $\begin{array}{l}\text { Parella } \\
\text { Emancipació }\end{array}$ & Formació i treball & $\begin{array}{l}\text { Xarxes socials } \\
\text { Ubicació ideològica }\end{array}$ \\
\hline Farid & $\begin{array}{l}17 \\
\text { Marroc } \\
6\end{array}$ & $\begin{array}{l}\text { Viu amb els pares I } \\
\text { els germans. No té parella. }\end{array}$ & $\begin{array}{l}\text { FP de grau mitjà } \\
\text { d'electromecànica } \\
\text { (en curs). No treballa. }\end{array}$ & $\begin{array}{l}\text { Els amics són de l'institut, } \\
\text { del barri, del casal del barri. } \\
\text { De tot arreu, però més } \\
\text { marroquins. Centre } \\
\text { no nacionalista. Classe } \\
\text { treballadora. }\end{array}$ \\
\hline Madiha & $\begin{array}{l}18 \\
\text { Marroc } \\
5\end{array}$ & $\begin{array}{l}\text { Viu amb els pares i } \\
\text { els germans. No té parella. }\end{array}$ & $\begin{array}{l}\text { Segon de batxillerat } \\
\text { tecnològic (en curs). } \\
\text { Treball ocasional. }\end{array}$ & $\begin{array}{l}\text { Amics de l'institut, del barri, } \\
\text { del casal del barri. De tot } \\
\text { arreu, però més marroquins. } \\
\text { Esquerra. Classe mitjana } \\
\text { assalariada. }\end{array}$ \\
\hline Salma & $\begin{array}{l}18 \\
\text { Marroc } \\
6\end{array}$ & $\begin{array}{l}\text { Viu amb els pares i els } \\
\text { germans. Parella d'origen } \\
\text { marroquí, nascut a } \\
\text { Barcelona. }\end{array}$ & $\begin{array}{l}\text { ESO i FP de grau mitjà } \\
\text { d'administratiu (en curs). } \\
\text { Treballs ocasionals sense } \\
\text { contracte. }\end{array}$ & $\begin{array}{l}\text { Amics de l'institut, del barri, } \\
\text { del casal del barri. De tot } \\
\text { arreu, però més marroquins. } \\
\text { Centre no nacionalista. } \\
\text { Classe treballadora. }\end{array}$ \\
\hline Aziz & $\begin{array}{l}19 \\
\text { Pakistan } \\
11\end{array}$ & $\begin{array}{l}\text { No té parella. Viu amb els } \\
\text { pares i amb la germana. }\end{array}$ & $\begin{array}{l}\text { Batxillerat. FP de grau } \\
\text { superior d'electrònica } \\
\text { (en curs). Treballa al } \\
\text { restaurant familiar. }\end{array}$ & $\begin{array}{l}\text { Té més amics catalans } \\
\text { que d'altres països. Centre } \\
\text { esquerra. Classe mitjana } \\
\text { assalariada. }\end{array}$ \\
\hline Hassan-1 & $\begin{array}{l}23 \\
\text { Marroc } \\
11\end{array}$ & $\begin{array}{l}\text { Viu amb els pares i els ger- } \\
\text { mans no independitzats. } \\
\text { Preferència per parella del } \\
\text { mateix origen, per evitar } \\
\text { problemes. }\end{array}$ & $\begin{array}{l}\text { FP de grau superior } \\
\text { d'electricitat (en curs). } \\
\text { Ha deixat dues vegades } \\
\text { la universitat. Treball } \\
\text { d'administratiu, contracte } \\
\text { indefinit. }\end{array}$ & $\begin{array}{l}\text { Amics de tot arreu: filipins, } \\
\text { catalans, marroquins, sud- } \\
\text { americans... Esquerra. } \\
\text { Classe treballadora. }\end{array}$ \\
\hline Nadia & $\begin{array}{l}26 \\
\text { Marroc } \\
20\end{array}$ & $\begin{array}{l}\text { Viu amb els pares. No té } \\
\text { parella. Prefereix una } \\
\text { parella marroquina, per } \\
\text { evitar conflictes familiars. }\end{array}$ & $\begin{array}{l}\text { BUP inacabat. Curs de } \\
\text { mediació intercultural. } \\
\text { Atur (ha fet diversos } \\
\text { treballs). }\end{array}$ & $\begin{array}{l}\text { Amics tots catalans. Posició } \\
\text { ideològica sense concretar. } \\
\text { Classe mitjana treballadora. }\end{array}$ \\
\hline Dolores & $\begin{array}{l}19 \\
\text { Perú } \\
19\end{array}$ & $\begin{array}{l}\text { Viu amb la mare i els } \\
\text { germans. Té parella } \\
\text { autòctona. Ho prefereix. }\end{array}$ & $\begin{array}{l}\text { No ha obtingut el } \\
\text { graduat. FP de grau mitjà } \\
\text { d'administratiu després } \\
\text { de fer la prova d'accés. } \\
\text { Vol acabar el graduat i } \\
\text { estudiar quiromassatge. } \\
\text { Busca feina. }\end{array}$ & $\begin{array}{l}\text { Tots els amics són autòctons. } \\
\text { Li costa relacionar-se amb } \\
\text { sud-americans. No manifesta } \\
\text { posicionament ideològic. } \\
\text { Classe mitjana assalariada. }\end{array}$ \\
\hline Paulina & $\begin{array}{l}27 \\
\text { Equador } \\
8\end{array}$ & $\begin{array}{l}\text { Viu amb la mare, } \\
\text { els germans i la filla } \\
\text { de } 5 \text { anys, nascuda a } \\
\text { Barcelona. No té parella. } \\
\text { Prefereix que sigui coèt- } \\
\text { nica, perquè la manera } \\
\text { de pensar i els costums } \\
\text { són diferents «si algun dia } \\
\text { regreso a mi país». }\end{array}$ & $\begin{array}{l}\text { Estudis de comerç i } \\
\text { administració a Equador } \\
\text { (inacabats). Treballa a } \\
\text { la botiga familiar. }\end{array}$ & $\begin{array}{l}\text { Amics internacionals, sobretot } \\
\text { Ilatins del barri, del treball... } \\
\text { Centre. Classe treballadora. }\end{array}$ \\
\hline
\end{tabular}


Taula 2. (continuació)

\begin{tabular}{llll} 
& & \multicolumn{3}{c}{ Dades socioculurals } \\
\cline { 3 - 4 } Situació jurídica & Discriminació & $\begin{array}{l}\text { Definició identitat } \\
\text { i pertinença } \\
\text { Identificació amb coetnics }\end{array}$ & Llengua \\
\hline Permís de residència. & $\begin{array}{l}\text { Mai s'ha sentit discriminat. } \\
\text { A vegades, la gent el mira «mala- } \\
\text { ment». }\end{array}$ & $\begin{array}{l}\text { Se sent marroquí i una mica } \\
\text { català, però poc. Poca identificació } \\
\text { amb elements identitaris. } \\
\text { Identificació amb coètnics. }\end{array}$ & \\
& & &
\end{tabular}

Permís de residència sense treball.

Permís de residència sense treball.

Permís de residència. Pendent de la nacionalitat ja tramitada.

Nacionalitat.

\section{Pendent d'obtenir la}

nacionalitat (ja tramitada).

Doble nacionalitat.

Permís de residència permanent i permís de treball.
Se sent ben tractada, no s'ha sentit discriminada: «Alguna vegada sents allò de "mora"».

S'ha sentit ben tractada, «com tothom». A l'escola, a la feina: «He tingut molta sort als treballs, ha sigut genial».

No problemes de discriminació. Molt ben tractat, però considera que la societat jerarquitza els col-lectius.

No discriminat, però ha viscut alguna situació negativa. Creu que es discrimina per ignorància i confusió.

Mai s'ha sentit discriminada.

No s'ha sentit discriminada. Considera que es discrimina més els pakistanesos i els marroquins.

No discrminació. Molt acceptada a tot arreu.
$70 \%$ marroquina i $30 \%$ espanyola. Creu que ser espanyol i català és diferent: «Potser marroquina i catalana». Identificació amb coètnics per l'idioma, la mentalitat, etc.

Mig de cada manera. Se sent al mig. Més d'aquí que d'allà. Més espanyola que catalana. Identificació ambivalent amb coètnics.

Musulmà al $100 \%$, català al $50 \%$ i pakistanès al $50 \%$. No és practicant, però se sent musulmà. No identificació amb coètnics, els veu diferents.

Marroquí $100 \%$. Musulmà també. S'identifica amb alguns coètnics.

Castellà amb els amics i poc català.

Amb els amics, àrab i castellà i a vegades, català.

Parla una mica de tot.

Català i castellà amb Castellà, àrab i poc català. els amics, i de tot a casa.

Castellà més que català (molta gent se li dirigeix en castellà).

Musulmana i espanyola: "Sóc musulmana i marroquina (és el mateix)». S'identifica amb els coètnics perquè provenen del mateix país.

Identitat: peruana. Nacionalitat: peruana. Cultura: espanyola. No s'identifica gens amb els coètnics. Sensació que li envaeixen l'espai.

Fusió. 50\% espanyola (més que catalana) i 50\% equatoriana. S'identifica amb els coètnics: «Todos somos iguales».
Castellà i a vegades català amb la filla. 
Taula 2. Comparativa de nois i noies entrevistats (continuació)

\begin{tabular}{|c|c|c|c|c|}
\hline \multicolumn{3}{|c|}{ Dades personals } & \multicolumn{2}{|r|}{ Dades sociodemogràfiques } \\
\hline Nom & $\begin{array}{l}\text { Edat, } \\
\text { Iloc de naixement o d'origen, } \\
\text { anys de residència }\end{array}$ & $\begin{array}{l}\text { Parella } \\
\text { Emancipació }\end{array}$ & Formació i treball & $\begin{array}{l}\text { Xarxes socials } \\
\text { Ubicació ideològica }\end{array}$ \\
\hline Hassan-2 & $\begin{array}{l}29 \\
\text { Marroc } \\
10\end{array}$ & $\begin{array}{l}\text { Viu amb la parella (que } \\
\text { prefereix que sigui del } \\
\text { Marroc) al barri del Raval, } \\
\text { al pis que han deixat els } \\
\text { pares. }\end{array}$ & $\begin{array}{l}\text { No va acabar els estudis } \\
\text { de secundària al Marroc } \\
\text { i tampoc va seguir-los } \\
\text { a Barcelona. Estudis a } \\
\text { Barcelona de castellà, } \\
\text { català, serigrafia i } \\
\text { informàtica. Vol estudiar } \\
\text { màrqueting (per la feina). } \\
\text { Treball fix com } \\
\text { a comercial. }\end{array}$ & $\begin{array}{l}\text { De tot arreu, però la majoria } \\
\text { del Marroc. No es defineix } \\
\text { del tot, però «cap a } \\
\text { l'esquerra». Classe } \\
\text { treballadora. }\end{array}$ \\
\hline Gabriel & $\begin{array}{l}25 \\
\text { Colòmbia } \\
11\end{array}$ & $\begin{array}{l}\text { Viu amb els pares } \\
\text { i un germà. Té parella } \\
\text { autòctona. No manifesta } \\
\text { preferències. }\end{array}$ & $\begin{array}{l}\text { FP de grau superior de } \\
\text { construcció. Universitat: } \\
\text { Arquitectura Tècnica } \\
\text { (en curs). Vol estudiar un } \\
\text { postgrau per ser arquitec- } \\
\text { te civil. Treballa al despatx } \\
\text { d'un arquitecte. }\end{array}$ & $\begin{array}{l}\text { Tots els amics són } \\
\text { autòctons, la majoria de } \\
\text { l'institut. D'estrangers, } \\
\text { no en coneix. Esquerra. } \\
\text { Classe treballadora. }\end{array}$ \\
\hline César & $\begin{array}{l}24 \\
\text { Equador } \\
7\end{array}$ & $\begin{array}{l}\text { Viu amb la seva parella } \\
\text { i una filla de } 2 \text { anys, } \\
\text { nascuda a Barcelona, al } \\
\text { seu pis, que és de compra. } \\
\text { La parella és de l'Equador } \\
\text { i es van conèixer a } \\
\text { Barcelona. No preferències } \\
\text { per l'origen de la parella. }\end{array}$ & $\begin{array}{l}\text { Batxillerat fisicomatemàtic } \\
\text { a l'Equador. No ha seguit } \\
\text { estudis a Barcelona } \\
\text { (volia fer arquitectura o } \\
\text { enginyeria elèctrica). Treba- } \\
\text { lla en una cadena } \\
\text { de supermercats des de } \\
\text { fa cinc anys. Hi està fix. Vol } \\
\text { organitzar la seva pròpia } \\
\text { empresa per comerciar } \\
\text { amb l'Equador. }\end{array}$ & $\begin{array}{l}\text { Té amics de l'Uruguai } \\
\text { i espanyols, sobretot del } \\
\text { treball. Esquerres. Classe } \\
\text { treballadora. }\end{array}$ \\
\hline
\end{tabular}

- Heterogeneïtat de relacions i xarxes socials. Més relació amb coètnics per part dels nois i noies arribats amb més edat. Preconcepcions poc possibilistes sobre les parelles mixtes. Menys coneixement i ús del català.

- Es posicionen en la classe treballadora i mitjana assalariada. La seva ideologia està situada entre el centre i l'esquerra.

- Alguns d'aquests joves es perceben tractats com a immigrats arreu, però tenen la percepció de ser ben tractats per la societat i de no haver estat mai discriminats.

3. Joves amb identitat cultural i ètnica flexible, amb més vinculació amb el context social i cultural majoritari, associat a una llarga socialització i enculturació al país de destinació, com també un escàs sentiment de pertinença a la cultura d'origen relacionat amb vivències de discriminació social i laboral, malgrat que han seguit unes bones trajectòries escolars. Sintetitzant, la majoria d'aquests joves es caracteritzen per (taula 3):

- En aquest grup, hi tenim 3 noies i 5 nois. Aquests joves han fet una socialització i una enculturació de llarg recorregut al país de destinació amb 
Taula 2. (continuació)

Dades socioculurals

Definició identitat

i pertinença

Situació jurídica

Discriminació

Permís de residència permanent i permís de treball. Vol tramitar la nacionalitat.

Identificació amb coetnics

Nacionalitat.

Identitat colombiana: «De allí de treball. Tramitant la nacionalitat.
No recorda cap situació de discriminació. Creu que es discrimina els marroquins, perquè ho han viscut uns quants membres de la seva família.

Mig espanyol, mig musulmà. Més musulmà que marroquí, perquè és d'una zona berber: «Sóc marroquí però adoptat per Catalunya. Em sento molt bé». Nacionalitat: marroquina. Cultura: musulmana. Grup ètnic: marroquí. No s'identifica amb tots els coètnics. Solament amb alguns, depèn de la manera de vestir, de la imatge, etc.

No experiències de discriminació, però veu discriminació diàriament amb altres persones d'origen immigrat. pero un poco adaptado aquí». S'identifica amb alguns coètnics. Depèn del temps de residència. Es veu diferent d'ells.

«Ecuatoriano hasta la muerte.»

Castellà. S'identifica amb alguns coètnics Li sembla que els de llarga residència «se han perdido».

Castellà.

Llengua

Castellà i àrab amb els amics.

raste

No s'ha sentit discriminat. Considera que la societat te preferències entre els immigrats de l'Amèrica Llatina i que als equatorians se'ls aprecia menys que als argentins o brasilers.

un fort sentiment de pertinença, sense perdre la lleialtat ni els referents d'origen.

- En general, s'identifiquen com a catalans i se senten plenament units a Catalunya i menys al que representa Espanya. Aquests sentiments no exclouen visions de mestissatge, de multiculturalitat i de viure «entre dos mons i cultures». Els joves d'origen marroquí es consideren occidentals amb ascendent musulmà o marroquí. N'hi ha alguns que no són practicants i els que ho són practiquen un islamisme molt relaxat, bàsicament per tradició familiar. Aquests joves parlen indistintament en català i en castellà, depèn de les relacions i dels espais de convivència. El noi xilè reacciona contra qualsevol identitat nacional i s'anomena "apàtrida», però amb identificació cultural catalana. Tots són competents per establir dinàmiques interculturals.

Famílies amb una gran diversitat de processos d'acomodació i aculturació. Fidelitat als orígens, però amb posicionaments socials i polítics crítics. Relacions intragrupals i/o intergrupals. Situació jurídica familiar estable, amb nacionalitat. Rols de gènere menys rígids i oposats que al país d'origen. 
Taula 3. Comparativa de nois i noies entrevistats

\begin{tabular}{|c|c|c|c|c|}
\hline \multicolumn{3}{|c|}{ Dades personals } & \multicolumn{2}{|r|}{ Dades sociodemogràfiques } \\
\hline Nom & $\begin{array}{l}\text { Edat, } \\
\text { lloc de naixement o d'origen, } \\
\text { anys de residència }\end{array}$ & $\begin{array}{l}\text { Parella } \\
\text { Emancipació }\end{array}$ & Formació i treball & $\begin{array}{l}\text { Xarxes socials } \\
\text { Ubicació ideològica }\end{array}$ \\
\hline Maria & $\begin{array}{l}21 \\
\text { Barcelona (Cuba-Angola) } 21\end{array}$ & $\begin{array}{l}\text { Viu amb els pares i les } \\
\text { germanes. No parella. }\end{array}$ & $\begin{array}{l}\text { Secundària, batxillerat i } \\
\text { FP de grau superior de } \\
\text { turisme (en curs). Treballs } \\
\text { d'hostessa. }\end{array}$ & $\begin{array}{l}\text { Amics de l'institut, de tot } \\
\text { arreu: espanyols, africans, } \\
\text { cubans, etc. Esquerra. } \\
\text { Classe treballadora. }\end{array}$ \\
\hline Omar & $\begin{array}{l}27 \\
\text { Marroc } \\
17\end{array}$ & $\begin{array}{l}\text { Independitzat, viu amb la } \\
\text { parella. Parella marroquina, } \\
\text { sense preferències. }\end{array}$ & $\begin{array}{l}\text { Batxillerat (no aca- } \\
\text { bat). FP de grau mitjà } \\
\text { d'automoció. Universitat } \\
\text { (en curs). Treball en enti- } \\
\text { tat d'immigrats. }\end{array}$ & $\begin{array}{l}\text { Amics de tot arreu: de } \\
\text { I"Amèrica Llatina, d'Europa, } \\
\text { de l'Àfrica. Xarxes socials molt } \\
\text { àmplies pel treball a l'entitat. } \\
\text { Esquerra. Classe mitjana } \\
\text { treballadora. }\end{array}$ \\
\hline Bilal & $\begin{array}{l}24 \\
\text { Barcelona (Marroc) } \\
24\end{array}$ & $\begin{array}{l}\text { S'ha independitzat. Viu } \\
\text { amb la parella, que és } \\
\text { autòctona. Indiferent } \\
\text { l'elecció de parella, } \\
\text { però li costaria si fos } \\
\text { marroquina. }\end{array}$ & $\begin{array}{l}\text { Ha cursat fins a primer } \\
\text { de batxillerat. FP de grau } \\
\text { mitjà d'administratiu. Vol } \\
\text { preparar-se la prova de } \\
\text { més grans de } 25 \text { anys per } \\
\text { fer l'accés a la universitat. } \\
\text { Treballa de vigilant de } \\
\text { seguretat. }\end{array}$ & $\begin{array}{l}\text { Amics de tot arreu. Dels que } \\
\text { menys en té, és de marro- } \\
\text { quins. Esquerra. } \\
\text { Classe treballadora. }\end{array}$ \\
\hline Yunus & $\begin{array}{l}22 \\
\text { Marroc } \\
13\end{array}$ & Viu amb els pares. & $\begin{array}{l}\text { ESO i FP de grau mitjà. } \\
\text { Treball en taller de } \\
\text { mecànica. }\end{array}$ & $\begin{array}{l}\text { La majoria d'amics són } \\
\text { espanyols. Esquerra. } \\
\text { Classe mitjana assalariada. }\end{array}$ \\
\hline Najat & $\begin{array}{l}28 \\
\text { Barcelona (Marroc) } \\
28\end{array}$ & $\begin{array}{l}\text { Viu amb els pares i ger- } \\
\text { mans no independitzats. } \\
\text { No li dóna importància a } \\
\text { l'origen de la parella. Ha } \\
\text { tingut parella autòctona. }\end{array}$ & $\begin{array}{l}\text { COU. Curs } \\
\text { d'administrativa. Curs } \\
\text { de mediació intercultural } \\
\text { (actual). Vol estudiar } \\
\text { Treball Social. Atur. Ha } \\
\text { treballat d'administrativa. }\end{array}$ & $\begin{array}{l}\text { Amics de tot arreu. Centre, } \\
\text { no nacionalista. Classe } \\
\text { treballadora. }\end{array}$ \\
\hline Layla-1 & $\begin{array}{l}22 \\
\text { Marroc } \\
10\end{array}$ & $\begin{array}{l}\text { Viu amb els pares } \\
\text { i germans. Té parella } \\
\text { del Marroc (viu al Marroc, } \\
\text { però vol venir a Barcelo- } \\
\text { na). Prefereix una parella } \\
\text { marroquina. }\end{array}$ & $\begin{array}{l}\text { Batxillerat, FP de grau } \\
\text { superior de comerç } \\
\text { internacional i FP de grau } \\
\text { superior d'educació infan- } \\
\text { til i curs de mediació inter- } \\
\text { cultural (en curs). Atur. Ha } \\
\text { treballat d'administrativa. }\end{array}$ & $\begin{array}{l}\text { Amics autòctons (dels } \\
\text { estudis). Esquerra. } \\
\text { Classe treballadora. }\end{array}$ \\
\hline Youssef & $\begin{array}{l}30 \\
\text { Marroc } \\
26\end{array}$ & $\begin{array}{l}\text { Independitzat. Viu amb } \\
\text { amics. Pis de lloguer a } \\
\text { l'Eixample. No parella. } \\
\text { No té preferències. }\end{array}$ & $\begin{array}{l}\text { Graduat. FP de grau mitjà. } \\
\text { Universitat (prova d'accés } \\
\text { als més grans de } 25 \text { anys). } \\
\text { Educació social (acabat). } \\
\text { Vol estudiar Antropologia. } \\
\text { Tècnic auxiliar en immi- } \\
\text { gració en un Ajuntament } \\
\text { de l'àrea metropolitana de } \\
\text { Barcelona. }\end{array}$ & $\begin{array}{l}\text { Amics d'arreu del món, però } \\
\text { més d'autòctons. Esquerra. } \\
\text { Classe treballadora. }\end{array}$ \\
\hline Carlos & $\begin{array}{l}24 \\
\text { Xile } \\
22\end{array}$ & $\begin{array}{l}\text { Viu amb la mare. No } \\
\text { parella. No preferències. }\end{array}$ & $\begin{array}{l}\text { Universitària (en curs). } \\
\text { Ha estudiat Filosofia i } \\
\text { actualment estudia Psico- } \\
\text { logia. Treballa de director } \\
\text { administratiu a la delega- } \\
\text { ció d'una associació. }\end{array}$ & $\begin{array}{l}\text { Tots els amics són catalans, } \\
\text { sobretot els companys } \\
\text { d'estudis. Progressista } \\
\text { nacionalista. Classe } \\
\text { treballadora. }\end{array}$ \\
\hline
\end{tabular}


Taula 3. (continuació)

\begin{tabular}{|c|c|c|c|}
\hline & \multicolumn{3}{|c|}{ Dades socioculurals } \\
\hline ituació jurídica & Discriminació & $\begin{array}{l}\text { Definició identitat } \\
\text { i pertinença } \\
\text { Identificació amb coetnics }\end{array}$ & Llengua \\
\hline acionalitat. & $\begin{array}{l}\text { Pel color de la pell, ha patit } \\
\text { agressions físiques: «M'han } \\
\text { dit de tot». }\end{array}$ & $\begin{array}{l}\text { És cubanocatalana, però molt } \\
\text { catalana, perquè sempre ha anat } \\
\text { a escoles catalanes: «M'identifico } \\
\text { amb tot de Catalunya». }\end{array}$ & $\begin{array}{l}\text { Castellà amb la mare i } \\
\text { català amb les germanes. }\end{array}$ \\
\hline acionalitat. & $\begin{array}{l}\text { Discriminació jurídica per } \\
\text { no tenir permís de treball. } \\
\text { Considera que es discrimina } \\
\text { per origen i que s'estableixen } \\
\text { jerarquies respecte als diferents } \\
\text { col·lectius. }\end{array}$ & $\begin{array}{l}\text { «Sóc fill del Marroc, adoptat per } \\
\text { Espanya i amb sentiment català.» } \\
\text { S'identifica amb tothom, sense fer } \\
\text { diferències de cap tipus. }\end{array}$ & $\begin{array}{l}\text { Català i castellà amb els } \\
\text { amics i de tot a casa. }\end{array}$ \\
\hline lacionalitat. & $\begin{array}{l}\text { S'ha sentit discriminat moltes } \\
\text { vegades. Considera que es jerar- } \\
\text { quitza les persones immigrades } \\
\text { segons el moment i el context. }\end{array}$ & $\begin{array}{l}\text { Catalanomarroquí. Nació catalana i } \\
\text { a vegades espanyola, cultura occi- } \\
\text { dental, grup ètnic catalans. } \\
\text { No s'identifica amb coètnics. } \\
\text { Li costa sentir-se com ells. }\end{array}$ & $\begin{array}{l}\text { Normalment, en castellà i a } \\
\text { vegades, en català. }\end{array}$ \\
\hline
\end{tabular}

Permís de residència. Actualment té probleme per renovar el permís.

Nacionalitat.

Residència permanent, tramitant la nacionalitat.

Nacionalitat.

Nacionalitat.
Discriminat quan buscava feina, per l'origen.

S'ha sentit discriminada pel color de la pell, pel nom, etc.

Discriminat quan buscava feina, per l'origen. No a l'institut.

S'ha sentit discriminat per la imatge. L'ha aturat la policia i li han demanat els papers. A la feina és el «marroquí».

Discriminació diverses vegades: al col-legi, al carrer, etc.
Hispanomarroquí. Més hispà que marroquí, més àrab que occidental. No s'identifica amb coètnics. Li costa identificar-se amb la mentalitat que tenen.

Catalanomusulmana (light) d'origen marroquí. S'identifica amb els coètnics, encara que acabin d'arribar. Se sent catalana, però els veu com a iguals.

Catalanomarroquina. Nacionalitat: marroquina i catalana. Cultura: catalana i marroquina. S'identifica amb els coètnics al Marroc, però no a Barcelona. Depèn del nivell d'estudis.

Es definex com a mestís. Nació: quan és al Marroc, més marroquí, quan és a Barcelona, més d'aquí. Cultura: occidental i musulmana. Grup ètnic: més amb marroquins (no gaire). No s'identifica gaire amb els coètnics: «Pel color de la pell, sí, per la manera de pensar, amb pocs».

Nació: apàtrida. Cultura: catalana i llatina. Grup ètnic: hispànic. No s'identifica amb tots els coètnics. Els veu molt diferents.
En castellà amb els amics i poc en català.

Català i castellà. Li costa més el català.

En castellà i poc en català.

A casa, castellà i àrab, i amb els amics, castellà i català.

Català i castellà. 
- Pel que fa a les xarxes socials dels joves, la majoria estableixen relacions àmplies $\mathrm{amb}$ molts amics de procedències múltiples. Els joves vinculats a associacions o entitats de barri són els que presenten relacions més variades. La identificació amb els coètnics és diversa. Des dels que no tenen cap relació amb els seus parells perquè no s'hi identifiquen, fins aquells que, per contra, expressen que s'identifiquen amb tothom i «viuen», solidàriament, les condicions de precarietat en què es troben els acabats d'arribar. Quant a l'elecció de parella, mostren preferències ben heterogènies.

- Continuïtat escolar amb trajectòries d'èxit. Treball més estable en nois, i noies en situació d'atur. Tots amb expectatives de millora laboral.

- Alguns joves se senten tractats com a nouvinguts pel color de la pell. Això provoca interrogants $\mathrm{i}$ replantejaments ètnics i culturals, perquè, tot $\mathrm{i}$ que han nascut al país de destinació i se senten catalans, no són tractats com a tals. Les vivències de discriminació són moltes i n'hi ha algunes d'importants: violència racista amb agressió física; discriminació pel color de la pell i per l'origen; discriminació a causa de la Llei d'estrangeria, que no els va permetre treballar; percepcions de discriminació per manca de comunicació i coneixement; discriminació en el moment de trobar feina pel fet de ser marroquina, tot i no tenir-ne trets físics, i discriminació per la imatge. Aquestes són algunes situacions viscudes per aquest grup de nois i noies, fet que no els impedeix identificar-se amb la societat majoritària i, alhora, mostrar-s'hi crítics. Malgrat aquestes experiències i percepcions, manifesten que se senten ben tractats per la societat. Alguns diuen que bé però «justet» $\mathrm{i}$ altres que cal fer-se respectar i reconèixer la discriminació i les desigualtats socials existents.

- Posicionament ideològic a l'esquerra amb actitud reivindicativa, que exerceixen des d'associacions i entitats. Ubicació en la classe treballadora.

4. Identitat cultural i ètnica flexible amb vinculació amb el context social i cultural majoritari, però amb més sentiment de pertinença a la cultura d'origen, amb percepció de discriminació escolar i/o laboral en les trajectòries viscudes. Aquests joves mostren les característiques següents (taula 4):

- Són pocs els nois i noies que presenten aquesta categoria tipus. Tenim 2 noies d'origen familiar marroquí, l'una nascuda al país de destinació i l'altra que hi va arribar quan tenia un any i mig, i 2 joves procedents de l'Amèrica Llatina que tenen la mateixa edat, arribats fa cinc i sis anys. Tenim 2 joves amb socialització i enculturació al país d'origen durant la infancia i l'adolescència i 2 joves d'origen marroquí que reinventen el vincle musulmà i fan un apropament a l'origen, però amb una identitat oberta. Són joves diferenciats entre ells, perquè n'hi ha dos que han viscut tota la vida al país de destinació i dos que hi han arribat avançada l'adolescència. La pràctica de la religió és el lligam més important amb el país d'origen per part de les noies musulmanes.

- Famílies amb fases inicials d'adaptació difícil a la societat. Sentiments d'estar entre dos mons. Famílies musulmanes practicants. Condicions 
jurídiques que corresponen al temps de residència. Rols de gènere menys rígids i oposats que al país d'origen, sobretot en les famílies amb més anys de residència.

- Les relacions d'amistat amb persones autòctones o coètniques estan determinades pel temps de residència. Pel que respecta a l'elecció de parella, hi ha diversitat de preferències.

- Trajectòries acadèmiques diverses, però persisteix la idea de continuar els estudis. Trajectòries laborals dominades per la precarietat i la temporalitat. Les causes són portar mocador i no tenir "permís de treball», fins i tot una noia ha estat víctima d'estafa laboral per part d'empresaris. Les mirades de superioritat i pejoratives dels autòctons s'afegeixen al sentiment de discriminació. En general, opinen que la societat discrimina i jerarquitza segons l'origen de les persones. No obstant aquestes vivències, la sensació d'una de les noies és que és ben tractada dintre dels àmbits on es mou, i el noi que ha patit agressions racistes i forta discriminació laboral se sent tractat de manera normal, «ni bé ni malament».

- Posicionaments a la classe treballadora i a l'esquerra ideològica.

Analitzats aquests quatre tipus d'identitats flexibles, cal dir que són tendències observades en el grup de joves entrevistats, que no s'han de donar pas en altres nois i noies amb característiques semblants. ${ }^{9}$. Que tots els joves construeixin identitats flexibles explica la no-determinació única i exclusiva de cap dels factors analitzats. Tots interactuen i els contextos influeixen de diverses maneres en cadascun dels nois i noies i en les seves biografies i trajectòries personals. Fet aquest aclariment, la pregunta és si hi ha relació directa entre les situacions analitzades i la identitat. Les troballes fonamentals de la recerca indiquen que es detecta una influència favorable a les identitats flexibles i a un sentiment de pertinença més gran amb la societat de destinació; a més anys de residència; al fet d'haver nascut al país de destinació o quan el reagrupament familiar es produeix en edat infantil (coincidint amb les aportacions de Fangen et al., 2010); si se segueix l'escolarització primària i secundària al país de destinació; quan la relació familiar no presenta conflictes culturals i les famílies realitzen una adaptació i una acomodació sense problemàtiques específiques, amb situació jurídica regularitzada i obtenció de la nacionalitat; quan s'obté el permís de treball, ja que treballar obre les portes al desenvolupament, al creixement i a l'emancipació personal; si les relacions i les xarxes socials són obertes i ajuden a adquirir habilitats culturals que assegurin una enculturació, una aculturació i una adaptació amb èxit; quan no es viuen trajectòries de marginació; en el cas que no es tingui una percepció social autonegativa ni inferioritzadora, i si no es pateixen vivències de discriminació, xenofobia o racisme importants. No obs-

9. Aquesta agrupació i aquesta anàlisi responen a la necessitat d'entendre i d'explicar quines diferències significatives trobem entre uns joves i els altres, quins elements es repeteixen $\mathrm{i}$ quins poden estar incidint en les identitats i les pertinences. Evidentment, no es tracta d'una classificació rígida, perquè no hi ha límits definits entre unes tipologies i les altres. A més, hi ha algunes característiques que es repeteixen. 
Taula 4. Comparativa de nois i noies entrevistats

\begin{tabular}{|c|c|c|c|c|}
\hline \multicolumn{3}{|c|}{ Dades personals } & \multicolumn{2}{|r|}{ Dades sociodemogràfiques } \\
\hline Nom & $\begin{array}{l}\text { Edat, lloc de naixement } 0 \\
\text { d'origen, anys de residència }\end{array}$ & $\begin{array}{l}\text { Parella } \\
\text { Emancipació }\end{array}$ & Formació i treball & $\begin{array}{l}\text { Xarxes socials } \\
\text { Ubicació ideològica }\end{array}$ \\
\hline Fàtima & $\begin{array}{l}20 \\
\text { Marroc } \\
19\end{array}$ & $\begin{array}{l}\text { Viu amb els pares i } \\
\text { germans. No té parella. }\end{array}$ & $\begin{array}{l}\text { Universitària (en curs). } \\
\text { Treballs diversos: en } \\
\text { un forn que també } \\
\text { és cafeteria, al zoo i } \\
\text { administrativa d'Atenció } \\
\text { Primària. }\end{array}$ & $\begin{array}{l}\text { Majoria d'amics de l'institut. } \\
\text { La majoria no són marroquins. } \\
\text { Esquerra. Classe treballadora. }\end{array}$ \\
\hline Fatiha & $\begin{array}{l}27 \\
\text { Barcelona (Marroc) } \\
27\end{array}$ & $\begin{array}{l}\text { Viu amb els pares i } \\
\text { germans. Prefereix que } \\
\text { la parella sigui marroquina } \\
\text { per la religió, però no li } \\
\text { importa especialment. }\end{array}$ & $\begin{array}{l}\text { Secundària i FP de grau } \\
\text { mitjà d'administratiu. } \\
\text { Treball d'administrativa. }\end{array}$ & $\begin{array}{l}\text { Últimament té molts amics } \\
\text { del Marroc, però també molts } \\
\text { d'autòctons. Esquerra. Classe } \\
\text { treballadora. }\end{array}$ \\
\hline J. Pablo & $\begin{array}{l}23 \\
\text { Equador } \\
5\end{array}$ & $\begin{array}{l}\text { Viu amb els pares, els } \\
\text { germans, les parelles } \\
\text { dels germans i la filla de } \\
\text { la germana. Parella colom- } \\
\text { biana. No té preferències } \\
\text { mentre sigui la noia amb } \\
\text { qui es trobi bé. }\end{array}$ & $\begin{array}{l}\text { Batxillerat amb espe- } \\
\text { cialització en tècnic } \\
\text { industrial en electrònica } \\
\text { (a l'Equador). Vol estudiar } \\
\text { FP de grau superior } \\
\text { d'electrònica. Treballa de } \\
\text { polidor de metalls en una } \\
\text { empresa d'alumini. Vol } \\
\text { estudiar per treballar } \\
\text { en allò que li agradi. }\end{array}$ & $\begin{array}{l}\text { Amics de tot arreu. Molts } \\
\text { de colombians i pocs } \\
\text { d'equatorians. Està en } \\
\text { un equip de futbol federat, } \\
\text { integrat principalment per } \\
\text { colombians. Centreesquerra. } \\
\text { Classe treballadora. }\end{array}$ \\
\hline Virgínia & $\begin{array}{l}23 \\
\text { Equador } \\
6\end{array}$ & $\begin{array}{l}\text { Viu amb els pares, un } \\
\text { germà i una germana. } \\
\text { Queda una germana a } \\
\text { l'Equador i un germà i una } \\
\text { germana que són a Madrid. } \\
\text { Té parella autòctona. No } \\
\text { preferències. }\end{array}$ & $\begin{array}{l}\text { Batxillerat a l'Equador. } \\
\text { A Barcelona, cursos } \\
\text { d'informàtica i d'anglès. } \\
\text { Vol estudiar a la univer- } \\
\text { sitat quan li homologuin } \\
\text { els estudis cursats a } \\
\text { l'Equador. Treballs tempo- } \\
\text { rals sense contractes. }\end{array}$ & $\begin{array}{l}\text { Té amics i amigues de } \\
\text { I'Equador, Xile, el Marroc, } \\
\text { Colòmbia i autòctons. } \\
\text { Centre. Classe treballadora. }\end{array}$ \\
\hline
\end{tabular}

tant això, cal emfasitzar que són les polítiques d'immigració (acollida, inclusió, etc.) les que defineixen globalment les condicions d'inclusió o exclusió social.

\section{Conclusions}

La identitat flexible dels joves entrevistats es construeix a través del procés d'enculturació i socialització, en relació amb la cultura familiar, la cultura social, la negociació entre totes dues i l'adopció d'estratègies per mantenir-se fidels als referents d'origen i al fet d'estar integrats a la societat de destinació. Tots aquests joves demostren una gran capacitat adaptativa a contextos culturals i socials diversos. Fan una adaptació positiva ràpida a la societat de destinació i n'abracen aquells elements culturals que s'ajusten més bé a la personalitat i a la manera de ser pròpies. Adquireixen el do de la ubiqüitat. Se situen en la societat i en la cultura majoritàries, però se segueixen sentint part de la cultura i de la terra d'origen. Com a estratègia d'incorporació i d'integració social, 
Taula 4. (continuació)

Dades socioculurals

Definició identitat

i pertinença

Situació jurídica

Està tramitant la nacionalitat espanyola i vol conservar la marroquina

Nacionalitat.

Permís de residència i de treball. Sol-licitada la nacionalitat.

Permís de residència i treball.

S'ha sentti discriminada pel color de la pell i per l'origen, sobretot al carrer.
Molts sentiments de discriminació. A l'escola, pels nens i nenes. Al treball, pels companys

Discriminat pels patrons al treball moltes vegades. Quan ha estat sense papers, l'han explotat. També ha tingut problemes amb caps rapats.

Identificació amb coetnics

Catalana i musulmana. Més berber que marroquina. Intenta fer un equilibri, és més d'aquí. Vol que la vegin com les altres persones. No s'identifica amb els coètnics.
Llengua

Castellà i català

amb amics. Berber amb la família.

Català i castellà amb els amics. catalana. No espanyola. S'identifica amb els coètnics. Els veu com és ella.

Identitat llatina: «Soy la misma

Castellà persona i seguiré siéndolo». Nació: equatoriana. Cultura: d'aquí. S'identifica poc amb els coètnics. Els veu molt allunyats de com és ell: «Depende de la persona».
Equatoriana i espanyola. Nació: equatoriana. S'identifica amb la gent de l'Equador, però en vol conèixer d'altres països.

Castellà

alguns d'aquests joves es diferencien dels seus coètnics arribats recentment, a qui atorguen tots els plusos de diferenciació. Per a uns altres, la interacció amb joves d'orígens culturals i ètnics diversos és una estratègia d'obertura que mostra la voluntat de sortir dels límits del propi grup i obrir-se socialment, sense que això suposi estratègies de negació de l'adscripció ètnica. Cal destacar que en cap dels joves he trobat casos d'identitats reconvertides al català, amb pèrdua dels referents i vinculacions amb origen.

La inclusió d'aquests joves es produeix amb dificultats. Han de vèncer desigualtat d'oportunitats, manca d'alguns drets cívics i situacions de discriminació, racisme o xenofobia. La societat construeix la identitat de les persones immigrades vinculada a l'elaboració d'alteritats i representades en negatiu. En general, la imatge que té la societat està determinada per l'origen familiar i el procés migratori. Els atorga identitats imposades, diferenciades i, sovint, excloents, i predomina la categoria d'immigrat per sobre de la categoria de joves. El nom, el color de la pell i l'origen ètnic són els elements que circum- 
scriuen els nois i noies a una identitat tancada des de l'òptica social. Per fer-hi front, el jovent van forjant identitats de resistència positives, reconvertides finalment en identitats flexibles dotades d'estratègies i de capacitats per afrontar relacions interculturals i superar desigualtats socials.

No s'observen diferències significatives entre nois i noies fora del que imposen les relacions de gènere. La majoria de noies entrevistades fan un discurs que inclou la perspectiva de gènere i rebutgen reproduir la submissió de les seves mares o àvies. El masclisme és un element present en el seu relat, fins al punt que les més conscienciades i reivindicatives reclamen una identitat de dona per sobre de qualsevol altra identificació. El contacte cultural amb la societat majoritària fa qüestionar valors i principis que abans eren incontestables.

L'anàlisi comparativa realitzada en les quatre categories tipus permet afirmar que no hi ha una relació causa-efecte definida entre les situacions de discriminació viscudes i les identitats construïdes. Les identitats flexibles es construeixen precisament en la superació de desavantatges, limitacions i categoritzacions socials. Tots els joves biografiats mostren flexibilitat identitària, ja sigui amb apropament a la cultura d'origen o de destinació $\mathrm{i}$ amb discriminació o sense. No obstant això, i malgrat que és difícil conèixer l'abast de l'impacte real de la discriminació negativa en les identitats i les pertinences, perquè es produeix una barreja de sentiments i afectivitats, és una evidència que cap dels joves que ha seguit trajectòries d'èxit escolar i laboral, sense discriminació, se sent poc vinculat al context social i cultural majoritari. Contràriament, els que mantenen o han fet un viratge vers la identitat cultural i ètnica d'origen han viscut situacions de discriminació de manera reiterada o bé se senten percebuts com a immigrats permanents.

La discriminació negativa, les dinàmiques de diferenciació $\mathrm{i}$ les pràctiques no inclusores minen les expectatives dels joves i en condicionen la ubicació en l'estructura col-lectiva. L'estigmatització social i l'exclusió poden cronificar-se. Trobar-se, de manera reiterada, en condicions de desigualtat afecta negativament la identitat i el sentiment de pertinença a la societat d'acollida. L'adjudicació de dèficits de vinculació i adaptació a alguns grups (com ara el marroquí) barra l'accés a una tria lliure de la identitat i a l'elecció de les preferències, perquè són imposades a través dels discursos i dels imaginaris col-lectius. L'estructura d'oportunitats, les xarxes socials i els drets socials (educatius i laborals, principalment), culturals, polítics i jurídics asseguren capital social als joves i són arguments perquè gaudeixin d'inclusió a la societat d'acollida i perquè puguin aconseguir identitats flexibles, obertes i positives.

\section{Referències bibliogràfiques}

ALBA, Richard (2005). «Bright vs. blurred boundaries: Second-generation assimilation and exclusion in France, Germany, and the United States». Ethic and Racial Studies, 28 (1), gener, 20-49.

ALBA, Richard i WATERS, Mary C. (ed.) (2011). The next generation: Immigrant youth in a comparative perspective. Nova York i Londres: New York University Press.

Aparicio Gómez, Rosa i Tornos Cubillos, Andrés (2006). Hijos de inmigrantes 
que se hacen adultos: marroquies, dominicanos y peruanos. Madrid: Ministerio de Trabajo y Asuntos Sociales. Observatorio Permanente de la Inmigración. Secretaría de Estado de Inmigración y Emigración. Subdirección General de Información Administrativa y Publicaciones, document núm. 8.

BAIllet, Dominique (1999). «Les jeunes militants d'origine maghrébine et l'intégration à la française». Migrations société: Centre d'informations et d'études sur les migrations internationales. CIEMI, 11 (62), març-abril, 99-115.

BARTH, Frederik (1976). Los grupos étnicos y sus fronteras. Mèxic: Fondo de Cultura Económica.

BAUMAN, Zigmunt (2005). Identitat. València: Publicacions de la Universitat de València.

BenHabIB, Seyla (2000). Diversitat cultural, igualtat democràtica: La participació política en l'era de la globalització. València: Tàndem.

Berry, John W.; Phinney, Jean S.; Sam, David L. i Vedder, Paul (2006). Immigrant youth in cultural transition: Acculturation, identity and adaptation across national contexts. Mahwah, Nova Yersey i Londres: Lawrence Erlbaum Associates, Publishers.

CAMILleri, Carmel et al. (1990). «Identité et gestion de la disparité culturelle: essai d'une typologie». A: CAMILleri, Carmel et al. Stratégies identitaires. París: Presses Universitaires de France. Psychologie d'Aujourd'hui, 85-110.

CARrasCo, Sílvia (2003). «La escolarización de hijos e hijas de inmigrantes y de minorías étnico-culturales en España». Revista de Educación, 330, 99-136.

- (2005). «Interculturalidad e inclusión: Principios para evaluar la acogida al alumnado de origen extranjero». Aula de Innovación Educativa, 147, 64-68.

CARRASCO, Sílvia (ed.) (2004). Inmigración, contexto familiar y educación: Proyectos y experiencias de la población marroqui, ecuatoriana, china y gambiana. Bellaterra: ICE-UAB. Colección Educación y Sociedad; 15.

Carrasco, Sílvia (dir.); Borison, Andrea i Ballestin, Beatriz (2005). Infancia i immigració: tendències, relacions, politiques. Vol. II. Infancies, famílies i canvis socials a Catalunya [en línia]. Barcelona: Ajuntament de Barcelona. Institut d'Infancia i Món Urbà. CIIMU. Observatori de la Infancia i la Família, 11-148. <www.ciimu. org> [Consulta: maig 2011].

CARrasco, Sílvia i PÀMIES, Jordi (2008). «Alumnado extranjero y condiciones de escolarización: Datos disponibles y datos necesarios para comprender la desigualdad». Madrid: CEAPA. Revista Padres y Madres de Alumnos y Alumnas, 98, setembreoctubre, 19-23.

Carrasco, Sílvia; Pamies, Jordi i Bertran, Marta (2009). «Familias inmigrantes y escuela: Desencuentros, estrategias y capital social». Revista Complutense de Educación, 20 (1), 55-78.

CArrasco, Sílvia; PÀmies, Jordi i POnfERrada, Maribel (2011a). «Fronteras visibles y barreras ocultas: La experiencia escolar del alumnado marroquí en Cataluña y mexicano en California». Migraciones, 29. Universidad Pontificia de Comillas. Instituto Universitario de Estudios sobre Migraciones, 31-36.

Carrasco, Sílvia; PÀmies, Jordi; Ponferrada, Maribel; Ballestin, Beatriz i Bertran, Marta (2011b). «Segregación escolar e inmigración en Cataluña: aproximaciones etnográficas». A: GARCía CASTAÑO, Francisco Javier i CARRASCO, Silvia (eds.). Población inmigrante y escuela: Conocimientos y saberes de investigación. Textos reunidos en homenaje a Eduardo Terrén Lalana. Madrid: Ministerio de Educación, 367-400. Estudios Creade; 5. 
Carter, Prudence L. (2005). Keepin' it Real scholl succes beyond black and white. Oxford: Oxford University Press.

CASTEL, Robert (2007). La discrimination négative: Citoyens ou indigènes? París: Éditions du Seuil et La République des Idées.

Castells, Manuel (1998). L'era de la informació: El poder de la identitat. Barcelona: UOC.

Delpino Goicoechea, M. Antonieta (2007). La inserción de los adolescentes latinoamericanos en España: algunas claves [en línia]. Madrid: Ministerio de Trabajo y Asuntos Sociales. Subdirección General de Información Administrativa y Publicaciones. <www.mtas.es> [Consulta: abril 2010].

Departament d'Estadística. Ajuntament de Barcelona [en línia]. <www.bcn.es/ estadistica> [Consulta: setembre 2011].

DOMíngUEZ, Obdúlia i DAZA, Lídia (2008). Trajectòries laborals del jovent immigrant reagrupat: marroquí i equatorià [en línia]. Barcelona: Secretaria de Joventut. Observatori de la Joventut. Generalitat de Catalunya. <www.gencat.cat> [Consulta: abril 2010].

ERIKSEN, Thomas H. (1993). Ethnicity and Nationalism: Anthropological Perspectives. Londres i Chicago: Pluto Press.

Esteva-Fabregat, Claudio (1984). Estado, etnicidad y biculturalismo. Barcelona: Península. Homo Sociologicus.

- (1993). Cultura, sociedad y personalidad. Barcelona: Anthropos. Editorial del Hombre.

FANGEN, Katrine (2010). «Social exclusion and inclusion of young immigrants: Presentation of an analytical framework». Young 2010 [en línia], 18 (2), 133-156. <http://you.sagepub.com/content/18/2/133> [Consulta: desembre 2011].

FANGEN, Katrine; Fossas, Kirsten i MoHN, Ferdinand A. (2010). Inclusion and exclusion of young adult migrants in Europe. Surrey: Ashgate Publishing Limited. Mpg Books Group.

FAngen, Katrine; Johansson, Thomas i Hammaren, Nils (2012). Young migrants: Exclusion and belonging in Europe. Hampshire: Palgrave Macmillan.

FeIXA, Carles (dir.); PORZIO, Laura i ReCiO, Carolina (coords.) (2006). Jóvenes «latinos» en Barcelona: Espacio público y cultura urbana. Barcelona: Anthropos. Ajuntament de Barcelona. Consorci Institut d'Infancia i Món Urbà.

FUNDACIÓN FOESSA (2008). VI Informe sobre exclusión y desarrollo social en España 2008. Madrid: Fundación FOESSA. Cáritas Española.

- (2012). Exclusión y desarrollo social en España [en línia]. Madrid: Fundación FOESSA. Cáritas Española. <http://www.caritas.es/imagesrepository/CapitulosPublicaciones/4314/EXCLUSION\%20Y\%20DESARROLLO\%20SOCIAL.\%20 Versi\%C3\%B3n\%20digital.pdf> [Consulta: abril 2012].

Furlong, Andy (2000). «La juventud en un mundo cambiante». A: «La juventud en transición». Revista Internacional de Ciencias Sociales [en línia], 164, juny. <http://www.unesco.org/new/fileadmin/MULTIMEDIA/HQ/SHS/ pdf/164fulldocspa164.pdf> [Consulta: abril 2012].

GIBSON, Margaret (1988). Accommodation without Assimilation: Sikh immigrants in an American High School. Nova York: Cornell University Press.

GIBSON, Margaret i CARRASCO, Sílvia (2009). "The education of immigrant youth: Some lessons from the US and Spain». Theory into Practice, 28 (4), 249-257.

INJUVE. INSTITUTO DE LA JUVENTUD (2009). Informe Juventud en España 2008 [en línia]. Madrid: Ministerio de Trabajo y Asuntos Sociales. <http://www.injuve.es/ contenidos.downloadatt.action? $\mathrm{id}=916511531>$ [Consulta: abril 2012]. 
JAZOuli, Adil (1995). «Les jeunes "Beurs" dans la société française». Migrations Société, 7 (38), març-abril, 6-24. Enquesta realitzada per Le Nouvel Observateur i La Marche du Siècle. CIEMI (Centre d'information et d'études sur les migrations internationales).

JulianO, Dolores (1998). «Los inmigrantes de segunda: La adscripción étnica asignada». A: Santamaria, Enrique i González Placer, Fernando (coord.). Contra el fundamentalismo escolar: Reflexiones sobre educación, escolarización y diversidad cultural. Barcelona: Virus.

LABRADOR FERNÁNDEZ, Jesús (2001). Identidad e inmigración: Un estudio cualitativo con inmigrantes peruanos en Madrid. Madrid: Universidad Pontificia de Comillas. Sociedad, Cultura y Migraciones.

LEE, Sara (2001). «La clase importa: Una comparación de los procesos de construcción de identidad étnica entre migrantes de segunda generación de clase trabajadora y de clase media. Inmigrantes coreanos en Nueva York». Araucania: Revista Iberoamericana de Filosofía, Política y Humanidades, 3 (6), segon semestre, 128-155.

Lepoutre, David (2001). Coeur de banlieue: Codes, rites et langages. París: Poches Odile Jacob.

MaAlouf, Amin (1999). Les identitats que maten: Per una mundialització que respecti la diversitat. Barcelona: La Campana.

MASSOT LAFON, M. Inés (2003). Jóvenes entre culturas: La construcción de la identidad en contextos multiculturales. Bilbao: Desclée de Brouwer.

MERENSTEIN, Beth (2001). «La construcción de identidad en las minorías: acerca de su importancia y sus consecuencias teóricas». Araucania: Revista Iberoamericana de Filosofí, Politica y Humanidades, 3 (6), segon semestre, 96-112.

Modood, Tariq (2011). «Capitals, Ethnic Identity, and Educational Qualifications». A: AlBA, Richard i WaTERS, Mary C. (ed.). The next generation: Immigrant youth in a comparative perspective. Nova York i Londres: New York University Press.

PÀMIES, Jordi (2008). Identitat, integració i escola: Joves d'origen marroqui a la periferia de Barcelona. Barcelona: Generalitat de Catalunya. Departament d'Acció Social i Ciutadania. Secretaria de Joventut. Premi Joventut 2006.

PORTES, Alejandro i APARICIO, Rosa (2009). La segunda generación en Barcelona: Un estudio longitudinal. Presentació de les dades preliminars de l'estudi a Fundació CIDOB, 29 de juny de 2009.

Portes, Alejandro i FernÁNDEZ-Kelly, Patricia (2007). «Sin margen de error: Determinantes del éxito entre hijos de inmigrantes crecidos en circunstancias adversas». Migraciones, 22. Madrid: Universidad Pontificia de Comillas. Instituto Universitario de Estudios sobre Migraciones, 47-78.

- (2008). "The adaptation of the immigrant second generation in America: Theoretical overview and recent evidence». The Center for Migration and Development [en línia]. Working Paper Series. Princeton University. Working Paper 08-02. <cmd. princeton.edu/papers/wp0802.pdf> [Consulta: juny 2011].

PORTES, Alejandro i ZHOU, Min (1993). "The new second generation: Segmented assimilation and its variants». The Annals of the Academy of Political and Social Science, 530 (novembre), 74-96.

PUjADAS, Juan José (1993). Etnicidad: Identitad cultural de los pueblos. Madrid: Eudema Antropología Horizontes.

PYKE, Karen (2001). «Estereotipos raciales y formación de identidades subétnicas entre nuevos estadounidenses de origen asiático». Araucania: Revista Iberoamericana de Filosofía, Politica y Humanidades, 3 (6), segon semestre, 112-127. 
Rinaudo, Christian; Gastaut, Yvan i Moussouni, Mouloud (1995). «La mise en contexte d'un drame: De l'immigration aux bandes ethniques?». Migrations Société. CIEMI (Centre d'information et d'études sur les migrations internationales), 7 (38), 25-35.

ROCA I CAPARÀ, Núria (2009). Construint identitats flexibles: Joves adults d'origen extracomunitari entre processos d'inclusió i exclusió social [en línia]. Universitat Autònoma de Barcelona. <www.tesisenxarxa.net/TDX-1222110-182109/index.html> [Consulta: abril 2012].

Rodrigo Alsina, Miquel (1999). Comunicación intercultural. Barcelona: Anthropos.

Rumbault, Ruben i PORTES, Alejandro (eds.) (2001). Ethnicities: Children of inmigrants in America. California: Russel-Sage Foundation.

SEN, Amartya (2007). Identidad y violencia: La ilusión del destino. Madrid: Katz.

Song, Miri (2003). Choosing ethnic identity. Cambridge: Polity Press.

SuÁrez-Orozco, Carola i SuÁreZ-Orozco, Marcelo (2003). La infancia de la inmigración. Madrid: Morata.

TORRABADELla, Laura i TEJERO, Elisabet (2005). Pioneres i pioners: Trajectòries biogràfiques de filles i fills de famílies immigrades a Catalunya. Barcelona: Fundació Jaume Bofill. Caixa Sabadell. Editorial Mediterrània.

Weller, Susie (2011). "Young people's social capital: complex identities, dynamic networks». A: REYNOLDS, Tracey. Young people, social capital and ethnic identity. Londres i Nova York: Routledge, 124-140.

ZHou, Min (1997). «Segmented Assimilation: Issues, controversies, and recent research on the New Second Generation». International Migration Review, 31 (4), número especial: «Immigrant adaptation and native-born responses in the making of americans», 975-1008. 